\title{
Histone H3.3 maintains genome integrity during mammalian development
}

\author{
Chuan-Wei Jang, Yoichiro Shibata, Joshua Starmer, Della Yee, and Terry Magnuson \\ Department of Genetics, Carolina Center for Genome Sciences, Lineberger Comprehensive Cancer Center, University of North \\ Carolina, Chapel Hill, North Carolina 27599-7264, USA
}

\begin{abstract}
Histone H3.3 is a highly conserved histone H3 replacement variant in metazoans and has been implicated in many important biological processes, including cell differentiation and reprogramming. Germline and somatic mutations in H3.3 genomic incorporation pathway components or in $\mathrm{H} 3.3$ encoding genes have been associated with human congenital diseases and cancers, respectively. However, the role of $\mathrm{H} 3.3$ in mammalian development remains unclear. To address this question, we generated H3.3-null mouse models through classical genetic approaches. We found that H3.3 plays an essential role in mouse development. Complete depletion of H3.3 leads to developmental retardation and early embryonic lethality. At the cellular level, H3.3 loss triggers cell cycle suppression and cell death. Surprisingly, H3.3 depletion does not dramatically disrupt gene regulation in the developing embryo. Instead, H3.3 depletion causes dysfunction of heterochromatin structures at telomeres, centromeres, and pericentromeric regions of chromosomes, leading to mitotic defects. The resulting karyotypical abnormalities and DNA damage lead to $\mathbf{p} 53$ pathway activation. In summary, our results reveal that an important function of $\mathbf{H} 3.3$ is to support chromosomal heterochromatic structures, thus maintaining genome integrity during mammalian development.
\end{abstract}

[Keywords: histone H3.3; genome integrity; transcriptional regulation; cell proliferation; apoptosis; mouse embryonic development]

Supplemental material is available for this article.

Received April 19, 2015; revised version accepted June 16, 2015.

H3.3 differs from the canonical replication-coupled H3 histones (H3.1/H3.2 in mammals) by only four to five amino acids, respectively, but has distinct expression patterns and chromatin incorporation mechanisms. Canonical H3 variants are expressed only during $S$ phase, and their incorporation is mediated by the CAF-1 chromatin assembly complex (Smith and Stillman 1989; Verreault et al. 1996; Tagami et al. 2004). In contrast, H3.3 is expressed throughout the cell cycle and is incorporated via a number of different pathways, including the CHD1 and ATRX chromatin remodeling complexes and the HIRA chaperone complex (Tagami et al. 2004; Konev et al. 2007; Drane et al. 2010; Lewis et al. 2010).

H3.3 is unevenly distributed in the genome, suggesting that it may have diverse roles. It is enriched in transcribed genes, enhancers, regulatory elements, and also heterochromatic repeats, including telomeres and pericentromeric regions (Wirbelauer et al. 2005; Loyola and Almouzni 2007; Goldberg et al. 2010; Szenker et al. 2011). A study with mouse embryonic stem (ES) cells showed that the HIRA complex deposits H3.3 in transcribed genes, while the ATRX complex delivers H3.3 to

Corresponding author: terry_magnuson@med.unc.edu Article is online at http://www.genesdev.org/cgi/doi/10.1101/gad.264150. 115 . telomeres and pericentromeric repeats (Goldberg et al. 2010).

H3.3 has been implicated in the epigenetic regulation of diverse biological processes. When incorporated into a nucleosome, H3.3 accumulates modifications associated with gene activation or open chromatin-including methylation on K4, K36, and K79 and acetylation on K9 and $\mathrm{K} 14$ - and is deprived of suppressive modifications, including K9 and K27 methylations (McKittrick et al. 2004; Loyola and Almouzni 2007). H3.3-containing nucleosomes are intrinsically unstable and promote gene activation, especially with histone H2A.Z coincorporation (Jin and Felsenfeld 2007; Jin et al. 2009; Chen et al. 2013). H3.3 maintains the somatic epigenetic memory in nuclear transferred Xenopus nuclei (Ng and Gurdon 2008) and supports differentiation of cultured murine muscle precursor cells (Harada et al. 2012). HIRA-dependent incorporation of $\mathrm{H} 3.3$ is also required for the reprogramming of nuclear transferred murine nuclei (Jullien et al. 2012; Wen et al. 2014), DNA replication and rRNA transcription in mouse zygotes (Lin et al. 2014), transcriptional recovery

(C) 2015 Jang et al. This article is distributed exclusively by Cold Spring Harbor Laboratory Press for the first six months after the full-issue publication date (see http://genesdev.cshlp.org/site/misc/terms.xhtml). After six months, it is available under a Creative Commons License (Attribution-NonCommercial 4.0 International), as described at http:// creativecommons.org/licenses/by-nc/4.0/. 
after genomic DNA damage in human cancer cell lines (Adam et al. 2013), and Polycomb-repressive complex 2 recruitment to developmentally regulated bivalent loci in mouse ES cells (Banaszynski et al. 2013). Furthermore, somatic mutations in H3.3-encoding genes cause various types of cancer in humans, underscoring its role in maintaining tissue homeostasis (Schwartzentruber et al. 2012; Behjati et al. 2013).

H3.3 is highly conserved across metazoans (Elsaesser et al. 2010; Szenker et al. 2011; Waterborg 2012), and its in vivo function has been studied in a number of different model organisms. In Drosophila, H3.3 is required only for fertility but is dispensable for both embryonic and postnatal development (Hodl and Basler 2009; Sakai et al. 2009). The fertility defects in H3.3-null flies can be rescued by ectopic expression of H3.2 (Hodl and Basler 2012). Likewise, growth defects of H3.2-null somatic clones can be rescued by overexpression of $\mathrm{H} 3.3$ in S phase (Hodl and Basler 2012), indicating that only the overall level of H3 histone, but not any specific variant, is essential in fly development. In Xenopus, HIRA-dependent H3.3 deposition is specifically required for early gastrulation and mesodermal marker gene activation, and, importantly, H3.2 overexpression cannot rescue the mutant phenotype (Szenker et al. 2012). Xenopus H3.3 promotes mesodermal gene activation by suppressing linker histone $\mathrm{H} 1$ incorporation and thus counterbalancing its chromatin-compacting effect, and an optimal ratio of the two is required to maintain a competent chromatin state for gastrulation to proceed (Lim et al. 2013). In zebrafish, reduced levels of H3.3 in the nuclei, caused by an aggregating dominant mutant H3.3, leads to defects in cranial neural crest cell differentiation (Cox et al. 2012), indicating tissue-specific sensitivity of $\mathrm{H} 3.3$ reduction in fish development.

As in flies and humans, the murine $\mathrm{H} 3.3$ protein is redundantly encoded by two genes: $H 3 f 3 a$ and $H 3 f 3 b$. Single knockouts and knockdowns of these two genes in mice have been reported (Couldrey et al. 1999; Bush et al. 2013; Lin et al. 2013; Tang et al. 2013, 2015; Inoue and Zhang 2014; Yuen et al. 2014). However, no one has reported a double knockout for both genes in the mouse embryo to reveal more fundamental functions of H3.3 in mouse development. Homozygotes of a H3f3a hypomorphic gene trap-inserted allele (Couldrey et al. 1999) and a targeted H3f3a-null allele (Tang et al. 2013) had reduced viability and male subfertility/infertility phenotypes. $H 3 f 3 b$ knockout mice also have reduced viability, and surviving adults are infertile (Bush et al. 2013; Yuen et al. 2014); even heterozygous males were reported to be infertile (Tang et al. 2013, 2015). Different phenotypes were observed in H3.3 knockdown mouse zygotes using different approaches; a nuclear envelope formation defect was observed in a study using siRNA, and a chromosome condensation change was observed in another study using morpholinos (Lin et al. 2013; Inoue and Zhang 2014). However, the knockdown experiments come with caveats. Both of these early stage phenotypes can be attributed to paternal genome nucleosome assembly defects during the histone-protamine exchange process after fertilization (Inoue and Zhang 2014) rather than an H3.3-specific effect. Furthermore, the off-target effects associated with either approach also render the conclusions less definitive (Jackson and Linsley 2010; Kok et al. 2015). Therefore, the role of H3.3 in mammalian development remains elusive.

In order to study H3.3's role in mouse development, we generated new targeted alleles for $H 3 f 3 a$ and $H 3 f 3 b$ in mice. In contrast to previous findings, our single-knockout mice, regardless of the gene, were overtly normal and fertile in both sexes. Complete depletion of H3.3 with double knockouts results in developmental retardation and embryonic lethality. H3.3-null embryos show reduced cell proliferation and increased cell death. Ablation of H3.3 in mouse ES cells leads to cell death and mitotic defects. The growth retardation phenotype can be rescued by a p53 deletion. Transcriptional profiling of these p53-null-rescued H3.3-null embryos by RNA sequencing (RNA-seq) revealed only limited changes to the global transcriptome. H3.3-null mouse embryonic fibroblasts (MEFs) without p53 can proliferate but show mitotic abnormalities associated with defects in chromosomal heterochromatic structures and genome instability phenotypes. Taken together, our data suggest that a major function of H3.3 in mammalian development is maintaining genome integrity through its function in supporting heterochromatin structures at telomeres, centromeres, and pericentromeric regions.

\section{Results}

H3.3 complete null leads to peri-implantation lethality, while perinatal lethality and male infertility occur in compound mutants

To guide our search for phenotypes, we first conducted expression analysis in various adult organs in wild-type mice for H3f3a, H3f3b, and, for comparison, H3.1/3.2encoding genes and stem-loop-binding protein (SLBP; which is expressed during $S$ phase to facilitate the translation of polyA-less histone genes) (Whitfield et al. 2000). Both $H 3 f 3 a$ and $H 3 f 3 b$ genes are ubiquitously expressed but differ in levels among tissues and are uncoupled from the expression of canonical H3 histones (Fig. 1A). The highest expression of both genes occurs in the testis, followed by the ovary. Canonical H3 expression is more associated with cell proliferation status; the thymus, with actively dividing immune cells, has the highest level of H3.1/H3.2 expression. SLBP is also highly expressed in the reproductive and immune systems. The data suggest a special role for $\mathrm{H} 3.3$ in germ cell development.

We targeted the $H 3 f 3 a$ and $H 3 f 3 b$ genes via homologous recombination in mouse ES cells using the same strategy for both: We inserted a promoter-less, splice acceptorNeo-positive selection cassette with a conditional reporter gene (EGFP for $H 3 f 3 a$, and tdTomato for $H 3 f 3 b$ ) into intron 1 (Fig. 1B; see Supplemental Fig. S1 for details) and flanked the first coding exon (exon 2) with loxP sites. Upon Cre-mediated deletion, the next available in-frame ATG produces a 16-amino-acid peptide (the full-length H3.3 has 136 amino acids), creating a functionally null allele. Correctly targeted clones were identified by PCR 
A

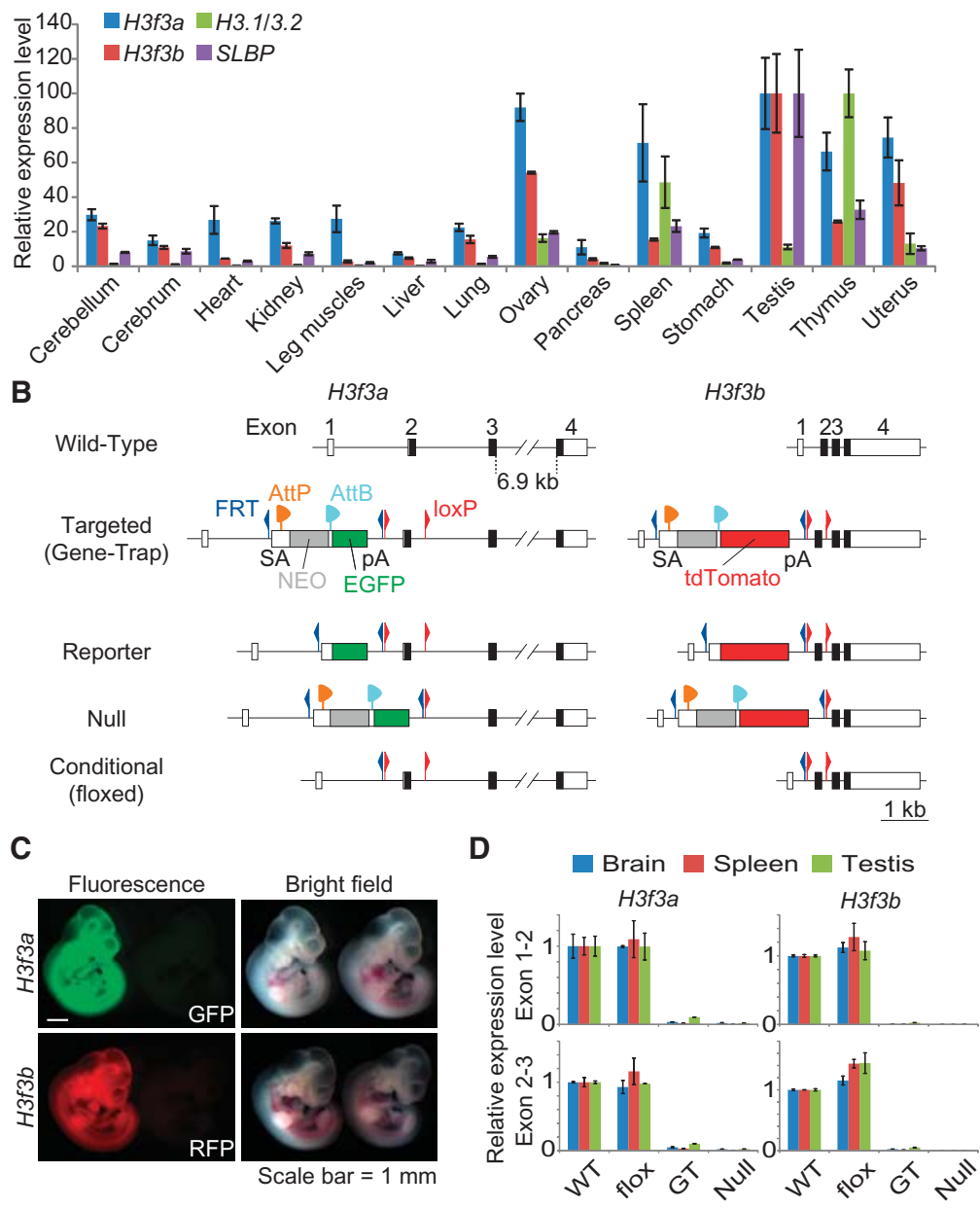

Figure 1. H3.3 gene expression and generation of H3.3 alleles. (A) Expression of $H 3 f 3 a, H 3 f 3 b, H 3.1 /$ 3.2 , and $S L B P$ in wild-type C57BL/6 adult mouse organs by quantitative PCR (qPCR). H3.1/H3.2 level was detected by using primers amplifying the consensus region of all of the annotated $\mathrm{H} 3.1 / \mathrm{H} 3.1$-encoding gene copies in the mouse genome. Levels of individual genes across tissues were normalized to $18 \mathrm{~S}$ rRNA, with the highest level set to 100. (B) Diagram of mutant $H 3 f 3 a$ and $H 3 f 3 b$ alleles created in this study. The initial targeted alleles were gene trap alleles with a splice acceptor and a polyA signal in intron 1. Fluorescent reporter alleles (EGFP for $H 3 f 3 a$, and tdTomato for $H 3 f 3 b$ ) were generated by $\phi \mathrm{C} 31$ integrase-mediated recombination between AttP and AttB sites. Null alleles were created by Cre-mediated deletion of the critical first coding exon (exon 2). Conditional (flox) alleles were created by deleting the gene trap cassette with FLP-mediated recombination between FRT sites. (NEO) Neomycin/G418 resistance gene. $(C)$ Expression of fluorescent reporter alleles. A reporter allele carrier embryonic day 10.5 (E10.5) embryo is shown with a wild-type littermate for either gene. $(D)$ Expression of $H 3 f 3 a$ and $H 3 f 3 b$ alleles in brain (cerebellum), spleen, and testis tissue from wild-type (WT; C57BL/6) and mutant animals homozygous with the indicated alleles by qPCR. Primer sets spanning intron 1 (exons 1 and 2) and intron 2 (exons 2 and 3 ) of each gene were used to access the transcription and splicing efficiency through introns 1 and 2, respectively. The standard error of the mean (SEM) is from two biological replicates $(n=2)$ for both $A$ and $D$. screens and reconfirmed with Southern blots (Supplemental Fig. S2). Mutant mice were generated through blastocyst injection. For both genes, the resulting gene trap allele was successfully transmitted through the germline and converted to a fluorescent protein reporter allele, a conditional allele, and a null allele by exposure to recombinases in vivo through crosses (Fig. 1B). The reporter alleles revealed ubiquitous expression of both genes during embryonic development (Fig. 1C). The gene-disrupting function of each allele was verified by transcription analysis in select organs from homozygous adult animals (Fig. 1D). The null allele completely abolishes expression of exon 2, and, importantly, the intronic insertions of FRT/loxP sites do not impede normal transcription or splicing through the introns, allowing for conditional deletion of $\mathrm{H} 3.3$ genes.

Single-gene knockout $\left(\mathrm{H} 3 \mathrm{f} 3 \mathrm{a}^{-/-}\right.$or $\left.\mathrm{H} 3 \mathrm{f} 3 \mathrm{~b}^{-/-}\right)$mice are overtly normal and fertile (data not shown). Furthermore, they can generate healthy and fertile progeny (in $\mathrm{H}_{3} \mathrm{Fa}^{-1}$ ${ }^{-} \times \mathrm{H} 3 \mathrm{f} 3 \mathrm{a}^{-/-}$or $\mathrm{H} 3 \mathrm{f} 3 \mathrm{~b}^{-1-} \times \mathrm{H} 3 \mathrm{f} 3 \mathrm{~b}^{-/-}$crosses), indicating that neither gene is required for the complete mouse life cycle.

To generate H3.3 complete null mutants, we intercrossed double-heterozygous animals $\left(\mathrm{H}_{3} \mathrm{f}_{3} \mathrm{a}^{-/+} ; \mathrm{H}_{3} \mathrm{f}_{3} \mathrm{~b}^{-/+}\right)$. Different staged embryos and postnatal pups were collect- ed, and the distribution of their genotypes is summarized in Figure 2A. At the late blastocyst stage (embryonic day 3.5 [E3.5]), $\mathrm{H} 3 \mathrm{f3a}^{-/-}$; $\mathrm{H} 3 \mathrm{f3} \mathrm{b}^{-/-}$double-knockout embryos were recovered at the expected Mendelian ratio. They were morphologically indistinguishable from control littermates (Fig. 2B). However, at E6.5, 2 d after implantation, double-knockout mutants were almost completely absent. The single double-knockout mutant recovered, of eight expected from 123 embryos, showed retarded growth (Fig. 2B). At E8.5, only two double-knockout mutants, of 12 expected, were recovered from 198 embryos. Similarly, these mutants had delayed growth. They morphologically resembled E7.5 wild-type embryos and had initiated Brachyury expression, a mesoderm marker (Herrmann 1991), indicating the correct progression of cell differentiation and patterning in double-knockout mutants (Fig. 2B). No double-knockout embryo was found at later stages. The low recovery rate and the phenotypes of double-knockout embryos after E6.5 indicate most of them either fail to implant or die shortly after due to a growth defect.

Compound mutants from the same crosses described above had other phenotypes. $H 3 f 3 a^{-/-} ; H 3 f 3 b^{-/+}$mutants $\left(A^{N u l l} B^{H e t}\right)$ die perinatally. All $A^{N u l l} B^{H e t}$ pups identified postnatally were dead (as early as postnatal day 0 [P0]), 
A

\begin{tabular}{|c|c|c|c|c|c|c|c|}
\hline \multicolumn{3}{|c|}{$\begin{array}{c}\text { Genotype } \\
\text { H3f3a } H 3 f 3 b\end{array}$} & $\begin{array}{c}E 3.5 \\
(\mathrm{~N}=80)\end{array}$ & $\begin{array}{c}E 6.5 \\
(N=123)\end{array}$ & $\begin{array}{c}E 8.5 \\
(N=198)\end{array}$ & $\begin{array}{c}E 18.5 \\
(N=122)\end{array}$ & $\begin{array}{c}\text { Birth } \\
(N=172)\end{array}$ \\
\hline +/+ & t/+ & (WT) & $4(5)$ & $2(8)$ & $14(12)$ & $12(8)$ & $24(11)^{\star \star}$ \\
\hline$-1+$ & $-1+$ & & $25(20)$ & $36(31)$ & $60(50)$ & $24(31)$ & $44(43)$ \\
\hline$-1+$ & $-1-$ & $\left(A^{\text {het }} B^{\text {null }}\right)$ & $8(10)$ & $10(15)$ & $24(25)$ & $9(15)$ & $16(22)$ \\
\hline$-1-$ & $-1+$ & ( $\left.A_{\text {null }}^{\text {het }}\right)$ & $6(10)$ & 21 (15) & $29(25)$ & $16(15)$ & $10(22)^{* \star} /$ all died \\
\hline$-1-$ & $-1-$ & (dKO) & $6(5)$ & $1(8)^{*}$ & $2(12)^{\star *}$ & $0(8)^{* *}$ & $0(11)^{* *}$ \\
\hline
\end{tabular}

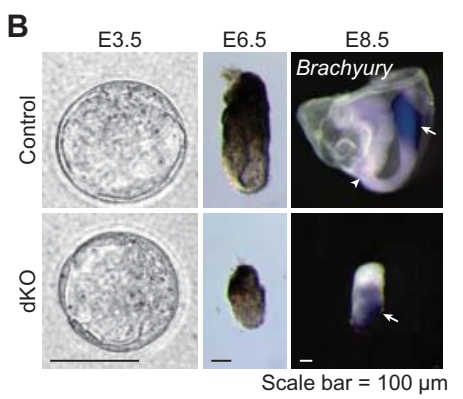

C

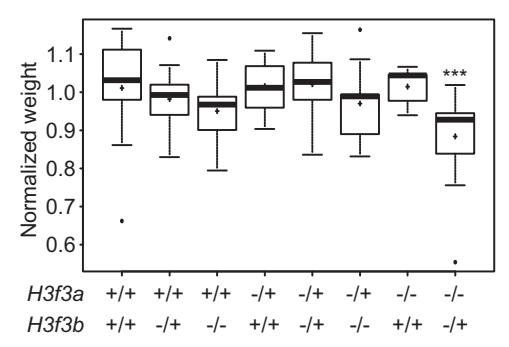

E

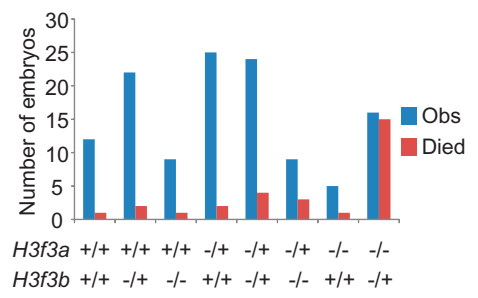

Observed (expected)

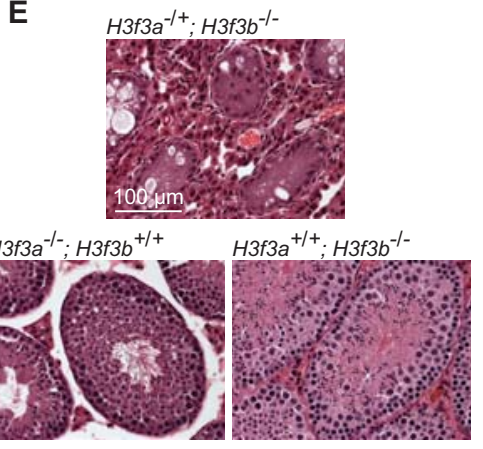

Figure 2. Lethality and fertility phenotypes of H3.3 gene knockout mutants. (A) The number of embryos/ pups of specific genotypes observed at different stages from $H 3 f 3 a^{-/+} ; H 3 f 3 b^{-/+}$mouse intercrosses. Numbers in parenthesis are expected numbers at the Mendelian ratio. The red background indicates that the observed numbers were significantly lower than expected. All of the $A^{\text {null }} B^{\text {het }}$ pups died after birth. Significant differences from the expected numbers are indicated by $\left(^{*}\right) P<0.05$ and $\left(^{* *}\right) P<0.01$ in $\chi^{2}$ test. (B) Double-knockout embryos $\left(\mathrm{H} 3 \mathrm{f} 3 \mathrm{a}^{-/-} ; \mathrm{H} 3 \mathrm{f} 3 \mathrm{~b}^{-/-}\right)$ and their littermate control $\left(\mathrm{H}_{3} \mathrm{f} 3 \mathrm{a}^{-/+} ; \mathrm{H} 3 \mathrm{f} 3 \mathrm{~b}^{-/+}\right)$at different stages. E8.5 embryos were hybridized with Brachyury probe, showing expression at the tail (arrow) and notochord (arrowhead) in the control and presumably the primitive streak in the doubleknockout mutant (arrow). (C) Box plot of body weight distribution of E18.5 C-sectioned embryos. Raw values were first normalized to the average weight in the litter. Significant difference from wild type (WT) is indicated. $\left(^{* * *}\right) P<0.001$ in ANOVA test. $(D)$ Survival of C-sectioned E18.5 embryos. Shown are total numbers of observed embryos (blue bars) and those that did not survive after C-section (red bars) in each genotype group. (E) Hematoxylin and eosin (H\&E) sections of testes from 6- to 8-mo-old adult males of the indicated genotypes. and their number was significantly lower than expected. When pups were delivered by C-section at E18.5, $1 \mathrm{~d}$ before birth, $A^{\mathrm{Null}} B^{\mathrm{Het}}$ mutants were found at the expected Mendelian ratio (Fig. 2A). However, they usually appeared smaller and weighed less than their wild-type littermates (Fig. 2C). In contrast to their littermates, most $A^{\text {Null }} B^{\text {Het }}$ mutants could not breathe properly and died (Fig. 2D), albeit having normal gross morphology (data not shown).

$\mathrm{H} 3 \mathrm{f} 3 \mathrm{a}^{-/+} ; \mathrm{H} 3 \mathrm{f} 3 b^{-/-}$mutant $\left(A^{\mathrm{Het}} B^{\mathrm{Null}}\right)$ males are infertile. $A^{\text {Het }} B^{\text {Null }}$ mice were born at the expected Mendelian ratio and survived to adulthood. However, they appeared slightly smaller than their littermates before weaning (data not shown). The mutant males could mate and produce vaginal plugs, but the mated wild-type females never became pregnant. Sections of $A^{\text {Het }} B^{\text {Null }}$ testes revealed complete loss of germ cells (Fig. 2E). $A^{\text {Het }} B^{\text {Null }}$ females are fertile (data not shown).

\section{H3.3 deletion leads to reduced cell proliferation and increased cell death in the embryo}

While double-knockout blastocysts appeared normal, possibly due to maternal deposits of H3.3 mRNA and protein, the post-implantation stage double-knockout embryos, which have more obvious phenotypes, were very rare.
To facilitate the study of H3.3 function in embryonic development, we used a conditional knockout approach to deplete H3.3 in the embryo with a Sox2-Cre transgene (Hayashi et al. 2002). When the transgene is transmitted through the paternal germline, Cre expression starts at the blastocyst stage in the inner cell mass, inducing global deletion of floxed alleles in the whole embryo. We crossed homozygous double-floxed females ( $H 3 f 3 a^{f 1 / f 1}$; $H 3 f 3 b^{f l / f 1}$ ) to double-heterozygous males with the Cre transgene $\left(\mathrm{H} 3 \mathrm{f} 3 \mathrm{a}^{-/+} ; \mathrm{H} 3 \mathrm{f}_{3} \mathrm{~b}^{-{ }^{-+}}\right.$; Sox $\left.2-\mathrm{Cr} e^{\mathrm{Tg} / O}\right)$ and harvested embryos at different time points. With this approach, H3.3 depletion occurs later than in the double-knockout crosses, resulting in later manifestation of mutant phenotypes. Indeed, we recovered H3.3 conditional knockout (cKO) mutant embryos $\left(H 3 f 3 a^{f l-}\right.$; H3f3b $b^{f l-}$; Sox2-Cre ${ }^{T g / O}$, referred to as Sox2-cKO hereafter) at the expected Mendelian ratio up to E10.5. After E10.5, most mutants were resorbed or being resorbed (data not shown). Sox2-cKO embryos were developmentally retarded at every time point examined (Fig. 3A). They appeared to grow in size, albeit without turning, but continuously fell behind their littermates as gestation proceeded. The overall patterning and cell differentiation, however, appears normal in Sox2cKO embryos, as judged by their morphology and Brachyury expression pattern visualized by whole-mount in situ hybridization at E8.5 (Fig. 3B). Notably, every Sox2- 
A
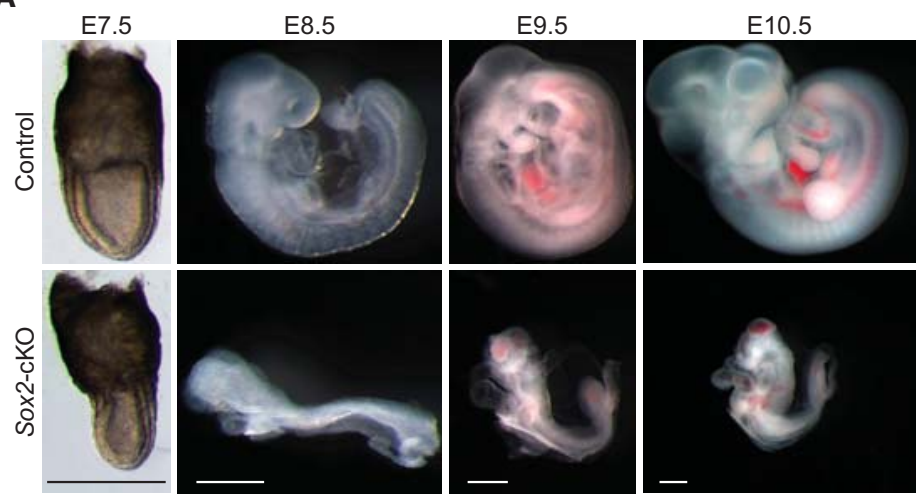

scale bar $=500 \mu \mathrm{m}$

B

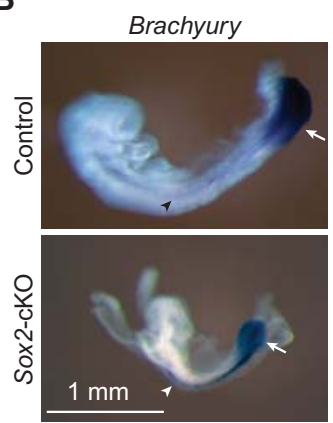

C

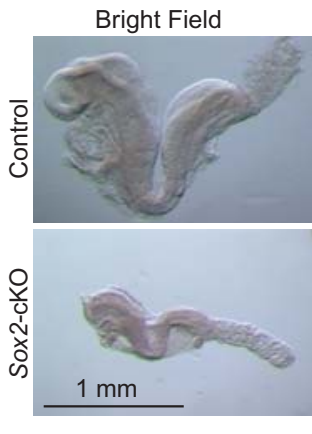

Lysotracker

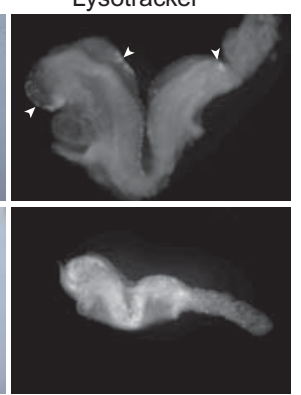

D

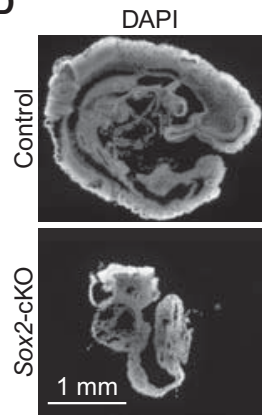

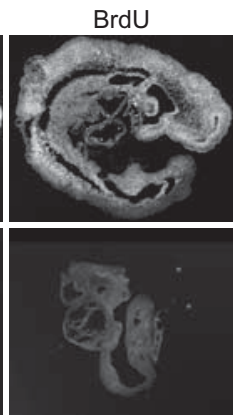

DAPI/BrdU

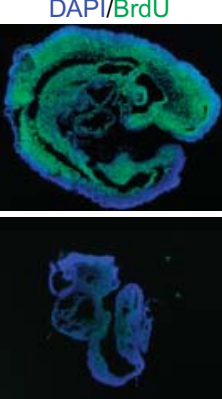

cKO embryo that we identified up to E10.5 had a beating heart at the time of dissection, suggesting that H3.3-null cells can differentiate properly.

We examined cell death and proliferation in Sox2-cKO mutants to identify the underlying cause of the growth retardation phenotype. Lysotracker staining detects acidification of cellular compartments, which correlates with occurrence of cell death (Fogel et al. 2012). Sox2-cKO mutants showed dramatically elevated signal in the whole embryo (Fig. 3C), indicating globally increased ectopic cell death. The BrdU incorporation assay gauges cell proliferation by staining cells that have gone through $S$ phase during the short pulse period and had BrdU incorporated in their genomic DNA. Sox2-cKO mutants showed a nearly complete absence of positive signal, in stark contrast to the ubiquitous strong staining of the controls (Fig. 3D), indicating strong cell cycle arrest or delay in H3.3null cells. Altogether, these data suggest that globally increased cell death and decreased cell proliferation contrib-
Figure 3. Sox2-cKO embryos died due to increased cell death and decreased cell proliferation. $(A)$ Embryos at different stages from crosses between $H 3 f 3 a^{f 1 / f 1}$; $H 3 f 3 b^{f 1 / f 1}$ females and $H 3 f 3 a^{f 1 /+}$; H3f3b $b^{f 1 /+}$; Sox2$\mathrm{Cre}^{\mathrm{Tg} / 0}$ males. For each stage, a control littermate $\left(H 3 f 3 a^{f l /+} ; H_{3} f 3 b^{f l /+}\right.$; Sox2-Cre $\left.e^{T g / O}\right)$ is shown with a Sox2-cKO mutant. (B) Brachyury expression detected by whole -mount in situ hybridization. Both the control and the Sox2-cKO mutant showed expression at the tail (arrow) and notochord (arrowhead). (C) E8.5 embryos stained with Lysotracker. Scattered positive spots in the control are indicated (arrowheads). (D) BrdU staining of sagittal sections of control and Sox2-cKO E9.5 embryos. The faint cytoplasmic signal in the Sox2-cKO/BrdU embryo section comes from nonspecific background staining. ute to the developmental retardation phenotype of the mutant embryos.

\section{H3.3 depletion leads to cell death and mitotic defects in ES cells}

We established conditional knockout ES cell lines with an inducible Cre transgene, CAG-CreER (Hayashi and McMahon 2002), with genotype: $H 3 f 3 a^{f l-}$; $H 3 f 3 b^{f l l-}$; $C A G$-CreER ${ }^{T g / O}$ (referred to as CreER-cKO) to study the cellular functions of H3.3. Upon 4-hydroxy-tamoxifen (TAM) treatment, Cre efficiently deleted the floxed alleles, and the cells quickly lost their $\mathrm{H} 3.3$ expression at both mRNA and protein levels (Fig. 4A,B).

H3.3 deletion triggered rapid cell death (Fig. 4C). When we attempted to expand H3.3 CreER-cKO cells after TAM treatment, the subsequent passages only resulted in cells with incomplete $\mathrm{H} 3.3$ deletion rapidly taking over (data not shown). This indicates that H3.3-null ES cells are 
A
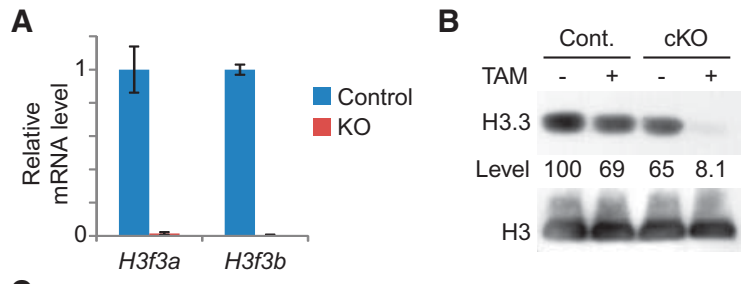

C

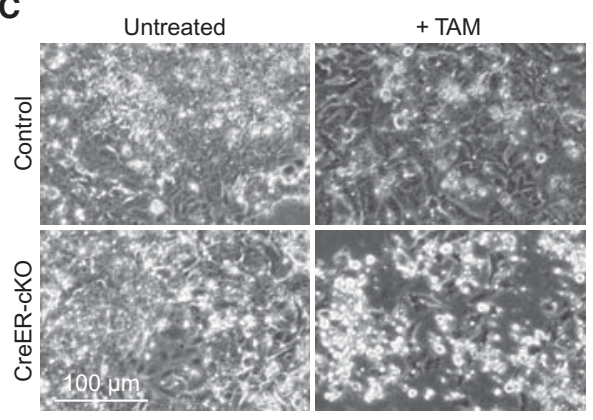

D

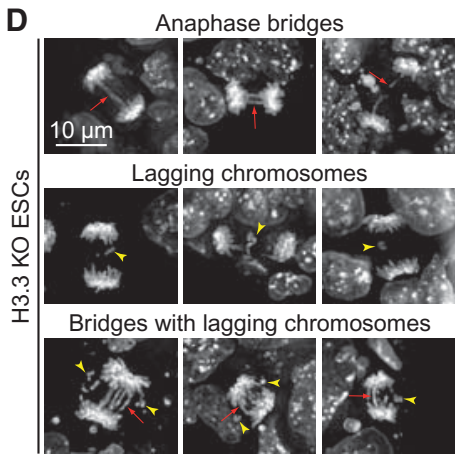

E

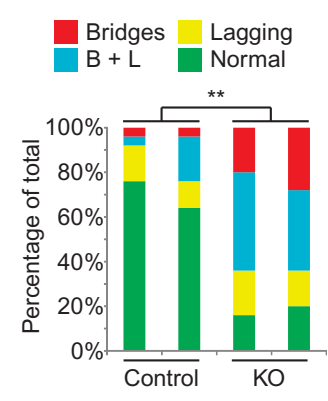

Figure 4. Cell death and mitotic defects in H3.3 knockout (KO) ES cells. (A) $H 3 f 3 a$ and $H 3 f 3 b$ expression in TAM-treated control $\left(H 3 f 3 a^{f l /+} ; H 3 f 3 b^{f l /+} ; C A G-C r e E R^{T g / O}\right)$ and CreER-cKO ES cells detected by RT-qPCR. SEM is from two biological replicates. (B) H3.3 protein levels in control and CreER-cKO ES cells with or without TAM detected by Western blot. The numbers below are calculated relative protein levels normalized to total $\mathrm{H} 3 .(C)$ Representative images of control and CreER-cKO ES cells with or without TAM treatment. Equal numbers of cells were seeded for each group at the beginning. $(D)$ Mitotic abnormalities with anaphase bridges (red arrow), lagging chromosomes (yellow arrowhead), or both were observed in H3.3 knockout ES cells. Cells were fixed and stained with DAPI. (E) Percentages of mitotic cells with abnormalities in control and H3.3 knockout ES cells; two lines of each were analyzed. Control is TAM-treated control cells. Twenty-five mitotic events were scored for each line. $\left(^{* *}\right) P<0.01$ in $\chi^{2}$ test.

either not viable or have a severe growth disadvantage. Interestingly, we observed sharply increased incidence of mitotic abnormalities in H3.3 CreER-cKO ES cells, including anaphase bridges and lagging chromosomes (Fig. $4 \mathrm{D}, \mathrm{E})$, indicating the involvement of mitotic failure in the cause of cell death.

\section{The p53 pathway mediates H3.3 mutant phenotypes}

With the mitotic phenotype in H3.3-null ES cells, we suspected the involvement of the p53 pathway in the mani-

festation of $\mathrm{H} 3.3$ knockout phenotypes and examined the expression of known p53 target genes p21 and Puma, involved in controlling cell senescence and apoptosis, respectively (Fig. 5A). Markedly, p21/Waf1, a tumor suppressor gene that induces cell cycle arrest (Warfel and El-Deiry 2013), is highly elevated in Sox2-cKO embryos at E8.5. Puma/BBC3, a BH3-only Bcl-2 family proapoptotic subclass gene (Hikisz and Kilianska 2012), is also up-regulated. These results indicate that, in Sox2-cKO mutants, the p53 pathway is activated and triggers cell cycle arrest and cell death through its downstream targets.

To provide further evidence of p53 involvement, we attempted to rescue the Sox2-cKO phenotypes by incorporating a p53-null mutation (Jonkers et al. 2001) into our conditional knockout crosses. The p53-null background dramatically rescued the Sox2-cKO mutant growth retardation phenotype up to E11.5, which was the latest stage they survived. Although there was some variation in the extent of rescue, the majority of $H 3 f 3 a^{f l l-}$; $H 3 f 3 b^{f l l-}$; Sox2-Cre ${ }^{T g / O} ; p^{2} 3^{-/-}\left(\right.$Sox2-cKO-p53 $\left.{ }^{\text {null }}\right)$ mutant embryos

A

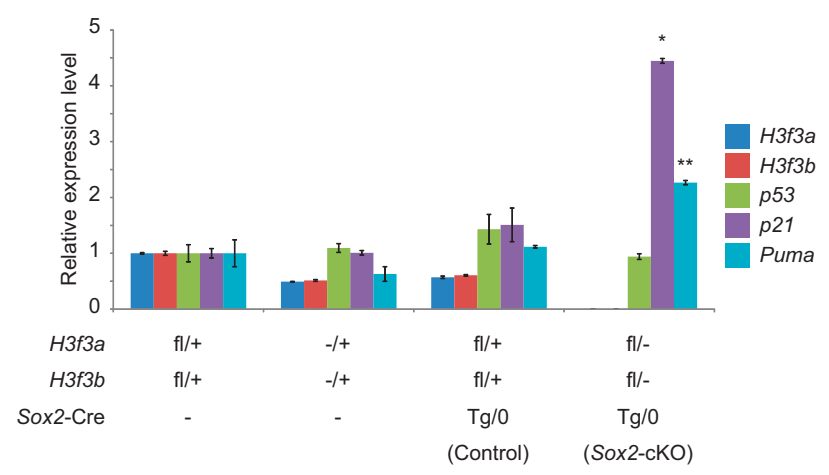

B

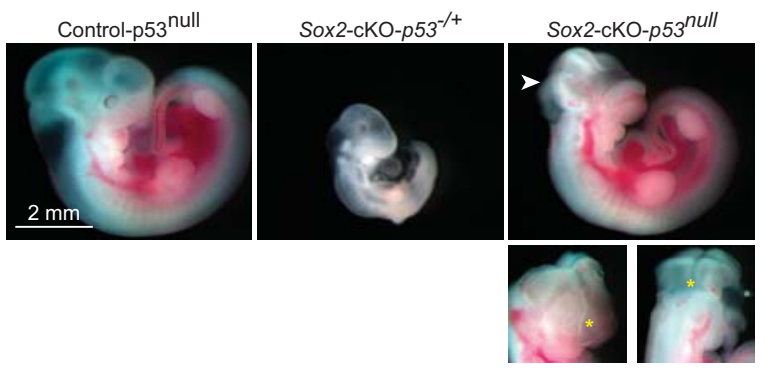

Figure 5. p53 involvement in mediating the H3.3 knockout phenotype. (A) Expression of $H 3 f 3 a, H 3 f 3 b$, p53, and two p53 target genes ( $p 21$ and Puma) in E8.5 embryos with the indicated genotypes. SEM is from two biological replicates. Significant difference from control in the Sox2-cKO is indicated. $\left({ }^{*}\right) P<0.05$; ${ }^{(* *)} P<0.01$ in one-tailed $t$-test. $(B)$ E10.5 littermates with con-

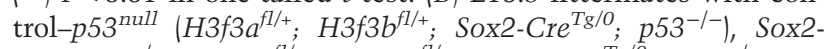

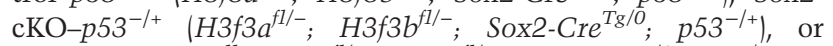

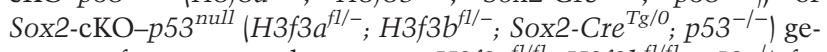
notypes from a cross between a $H 3 f 3 a^{f l / f 1} ; H 3 f 3 b^{f l / f 1} ; p 53^{-/+} \mathrm{fe}-$

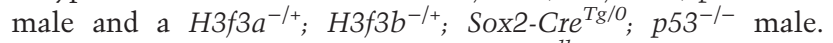
Neural tube disclosure in Sox2-cKO-p53 ${ }^{\text {null }}$ is indicated (arrowhead); the two images below show the arrowhead-indicated region (yellow asterisk) from different angles. 
were slightly smaller than their control littermates, with morphologically normal body structures and organs. However, neural tube closure defects were always observed in these rescued embryos (Fig. 5B). This dramatic rescue illustrates the pivotal role that p53 plays in $\mathrm{H} 3.3$ knockout phenotypes. However, the p53-null rescue did not fully support development to later stages; we observed resorptions of Sox2-cKO-p53 ${ }^{\text {null }}$ mutants and a sharp drop in their ratio after E10.5 (data not shown).

\section{Limited changes in the global transcriptome upon loss of H3.3}

To understand the role that H3.3 plays in transcriptional regulation, we examined the gene expression profiles of the Sox2-cKO-p53 ${ }^{\text {null }}$ rescued embryos by RNA-seq. Three mutant $\left(H 3 f 3 a^{f l /-} ; \quad H 3 f 3 b^{f l /-} ;\right.$ Sox2-Cre $e^{T g / O}$;

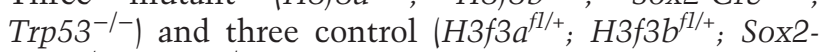
$\mathrm{Cre}^{\mathrm{Tg} / 0}$; Trp53 ${ }^{-1-}$ ) E10.5 male embryos were used in the sequencing experiment (Supplemental Fig. S3A). The targeted second exon's expression is completely abolished for both $H 3 f 3 a$ and $H 3 f 3 b$ genes, as shown in the University of California at Santa Cruz (UCSC) Genome Browser RNA-seq tracks (Supplemental Fig. S3B).

Because H3.3 is enriched in all transcribed genes (Wirbelauer et al. 2005; Goldberg et al. 2010; Szenker et al. 2011), we expected a large number of them to show significant changes in expression. After mapping the reads to the mouse reference genome $(\mathrm{mm} 9)$, we identified close to 14,000 expressed genes /defined as a gene with more than one count per million [CPM] in two or more samples) (Supplemental Tables S1, S2). A multidimensional scaling (MDS) plot showed that the H3.3-null and control embryos formed separate clusters, indicating that the two groups have distinctive gene expression patterns (Supplemental Fig. S3C). However, only $\sim 5 \%$ of the transcribed genes showed statistically significant changes (with false discover rate $[$ FDR $]<0.05$ cutoff) (Fig. 6A), and their distribution was tilted toward the genes with lower expression levels compared with the total population (Supplemental Fig. S3D). Among the genes significantly changed, $65 \%$ of them had a less than twofold difference, suggesting minimal biological effects (Fig. 6B). More genes were upregulated in the H3.3-null embryos $(\sim 66 \%$ of significantly changed genes) (Fig. 6B). In addition, most of the more severely affected genes, with greater than twofold differences, had relatively low expression levels (Supplemental Fig. S3E).

Because the RNA-seq analysis method (edgeR) normalizes for total read counts in each library, it cannot detect global expression shifts; e.g., a down-regulation of all transcribed genes in the H3.3-null embryos. To rule out this possibility, we selected six genes that did not show significant differences in the RNA-seq analysis and spanned a wide range of CPMs for RT-qPCR validation. The results were consistent with the RNA-seq analysis and showed that there was not a global expression shift (Supplemental Fig. S3F). Furthermore, there were no significant differences in total RNA output per embryo between the H3.3-null and control embryos (Supplemental Fig. S3G). Therefore,
A

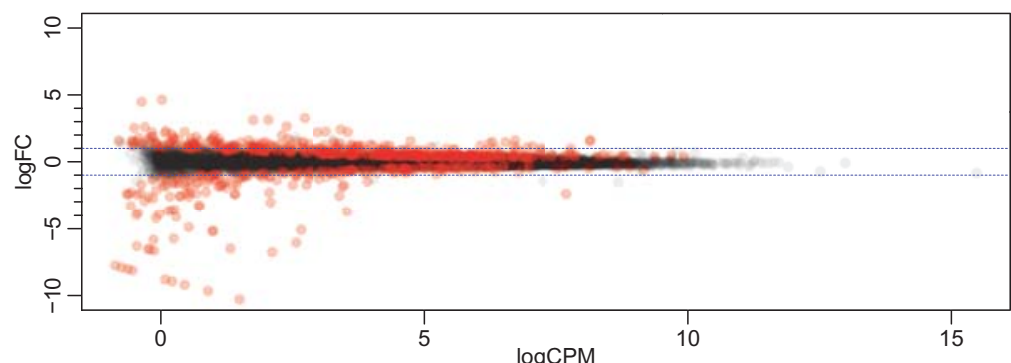

B

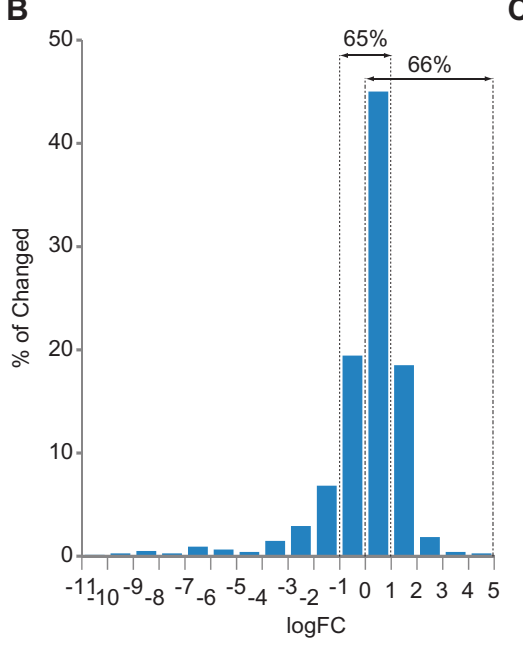

C

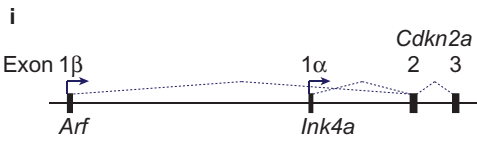

ii

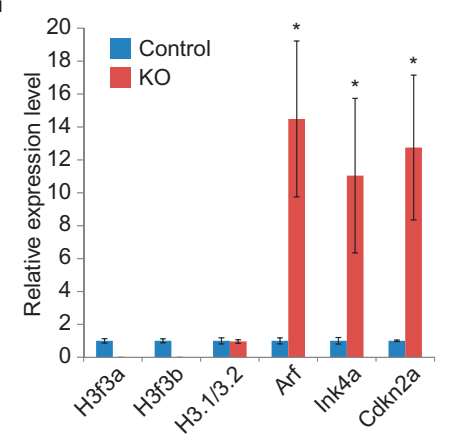

Figure 6. Differential expression analyses of H3.3null embryos in a p53-null background. $(A)$ The edgeR smear plot visualization of RNA-seq results. Each dot represents a gene; the $X$-axis is mean $\log _{2} C P M$, indicating expression level of the genes, and the $Y$ axis is $\log _{2}$ fold change $\left(\log _{2} \mathrm{FC}\right)$, indicating gene expression change upon $\mathrm{H} 3.3$ deletion. Genes with a significant change $(F D R<0.05)$ are plotted in red. The horizontal dashed blue lines mark the plus or minus twofold change range. $(B)$ Effect size distribution of significantly changed genes. Sixty-five percent of genes have changes between plus and minus twofold, and $66 \%$ of genes have positive changes. (C, panel i) Gene structure of Cdkn2a (cyclin-dependent kinase inhibitor 2A); two splice isoforms, Ink $4 a$ and Arf, are driven by different promoters and have different first exons ( $1 \alpha$ and $1 \beta$, respectively). (Panel ii) Relative expression levels of $H 3 f 3 a, H 3 f 3 b, H 3.1 / 3.2$, Arf (detected by primers spanning exons $1 \beta / 2$ ), Ink $4 a$ (detected by primers spanning exons $1 \alpha / 2)$, and $C d k n 2 a$ total output (detected by primers spanning exons $2 / 3$ ) in H3.3 knockout (KO) versus control embryos. $n=3 .\left(^{*}\right) P<0.05$ in one-tailed $t$-test. 
we can rule out the possibility of a global and proportional up-regulation/down-regulation of every gene in the H3.3null embryos. To determine whether transcription in specific genomic domains was susceptible to loss of H3.3, we examined the genomic distribution of significantly changed genes (Supplemental Fig. S3H), expecting to find down-regulated and up-regulated genes in separate clusters. However, we could not find any specific patterns and ruled out localized gene expression changes.

A recent report proposed a role for H3.3 in the silencing of endogenous retroviral elements in mouse ES cells (Elsasser et al. 2015); therefore, we specifically examined the expression of repetitive elements (REs) in our RNAseq data. However, statistical analysis did not find clear separation between the control and H3.3 mutant embryos by their RE expression patterns (Supplemental Fig. S3I). Furthermore, among the $>1000$ REs found expressed in the embryos, only one element ["(A) $n$ " element] showed a statistically significant change in the mutant embryos (Supplemental Fig. S3J; Supplemental Table S3). Therefore, H3.3's effect on the expression or suppression of REs in the developing embryo appears to be minimal.

Intriguingly, Cdkn2a (cyclin-dependent kinase inhibitor 2A), an important tumor suppressor gene (Kim and Sharpless 2006), was the second most highly up-regulated gene in the RNA-seq data analysis (the most up-regulated gene, leading by a very small margin of fold change, was a pseudogene) (Supplemental Table S2). Cdkn2a has two transcriptional isoforms produced by alternative promoter usage: The a promoter produces the Ink $4 a$ transcript, while the $\beta$ promoter leads to Arf expression (Fig. 6C, panel i). We confirmed the up-regulation of Cdkn2a by RTqPCR. Specific primers were designed to gauge Arf- or Ink $4 a$-specific expression or the total output of both transcripts. The results indicated that both transcription isoforms were up-regulated to similar levels in H3.3 knockout embryos relative to the control (Fig. 6C, panel ii). At the same time, we confirmed the complete deletion of H3.3 genes. We also examined the level of canonical H3, which was reported to be up-regulated in H3.3 mutant flies (Hodl and Basler 2009), but found no change.

The biological effects of the gene expression changes were analyzed by the Ingenuity Pathway Analysis software (http://www.ingenuity.com), with a FDR $<0.05$ cutoff. The canonic pathway (Supplemental Fig. S4; Supplemental Table S4) and disease and biofunction pathway (Supplemental Fig. S5; Supplemental Table S5) analyses suggested that the hematological and immune system development is most likely affected by these changes.

\section{H3.3 depletion leads to mitotic defects} and genome instability

The p53-null mutation enables derivation of H3.3 knockout/p53 ${ }^{\text {null }}$ MEF lines (from Sox2-cKO-p53 ${ }^{\text {null }}$ embryos). H3.3-null MEFs derived from Sox2-cKO embryos with wild-type $p 53$ grew very poorly and were extremely difficult to expand (data not shown). In contrast, H3.3 knockout $/ p 53^{\text {null }}$ MEFs grew well and were easily expanded, albeit slightly less proliferatively than MEFs derived from the control littermates. These robustly growing H3.3-null MEFs allowed us to explore the mechanisms behind the H3.3 depletion-triggered cell death and growth arrest. We used only early passage MEFs (passage 2 [P2] to P5) in our experiments to minimize the effect of the in vitro culture environment.

Interestingly, similar to the H3.3 knockout ES cells, H3.3 knockout MEFs showed dramatically increased mitotic defects, including lagging chromosomes and anaphase bridges (Fig. 7A,B). To test for the involvement of ATRX in the phenotype for its role in maintaining heterochromatic chromosome structures, we performed fluorescent in situ hybridization (FISH) with a telomeric probe and immunofluorescence with an antibody against ATRX. ATRX localization to the pericentrimetric heterochromatin appeared to be unaffected by loss of H3.3 even on the lagging chromosomes (Fig. 7A). We also performed chromatin immunoprecipitation (ChIP) to assess ATRX binding to telomeric sequence repeats in $\mathrm{H} 3.3$ knockout $/ p 53^{\text {null }}$ MEFs but observed no change compared with controls (Supplemental Fig. S6). In the mitotic cells with anaphase bridges, we observed telomere FISH signals in the middle of the bridging chromosomes (Fig. 7A), indicating dicentric chromosomes formed through telomeric fusions.

We made metaphase spreads and found dramatically increased numbers of cells with abnormal numbers of chromosomes in H3.3 knockout/p53 ${ }^{\text {null }}$ MEFs (Fig. 7C). The majority of them have chromosome gains. Loss of H3.3 appears to cause polyploidy and aneuploidy, presumably resulting from the faulty mitotic processes (Davoli and de Lange 2011; Ganem and Pellman 2012).

Finally, we observed elevated levels of S139 phosphorylation of histone H2A.X (rH2A.X) in H3.3 knockout/ p53 ${ }^{\text {null }}$ MEFs (Fig. 7D,E), a canonical marker for DNA double-strand breaks (Rogakou et al. 1998). This indicates increased DNA damage in H3.3 knockout cells.

\section{H3.3 is required for normal heterochromatin function at telomeres, centromeres, and pericentromeric regions}

To find the underlying cause of the mitotic defects in H3.3-null MEFs, we examined the integrity of telomeres, distribution of heterochromatic histone marks, and chromatin compaction at the telomeres, centromeres, and pericentromeric regions where $\mathrm{H} 3.3$ was reported to be enriched.

To determine whether $\mathrm{H} 3.3$ knockout $/ p 53^{\text {null }}$ MEF lines had aberrant telomere sister chromatid exchange (tSCE), we applied the chromosome orientation FISH (CO-FISH) technique (Williams et al. 2011). Significantly increased rates of tSCE events were observed in the H3.3-null MEFs (Fig. 8A,B), indicating excessive recombination events in telomeres as a result of compromised telomere structure or maintenance mechanisms (Bailey et al. 2004).

Changes in local histone marks can compromise the functions of telomeres and centromeres (Jones et al. 
A

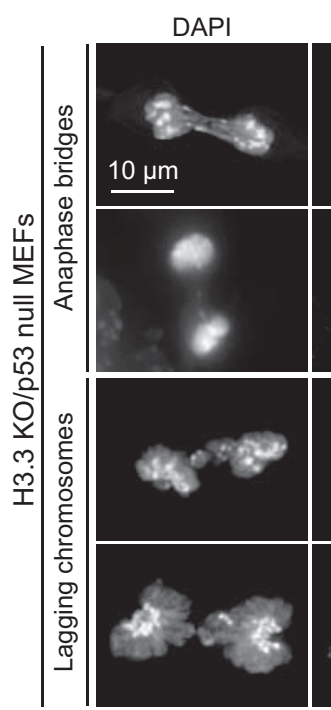

B

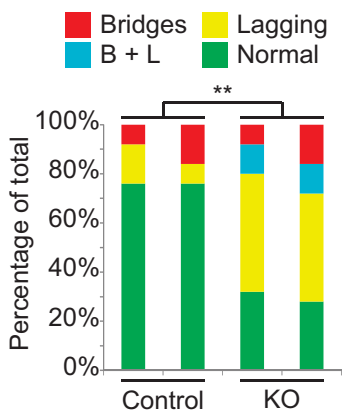

D

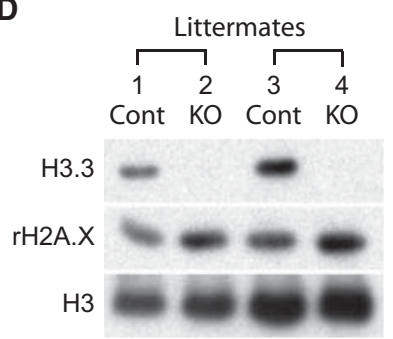

TelC

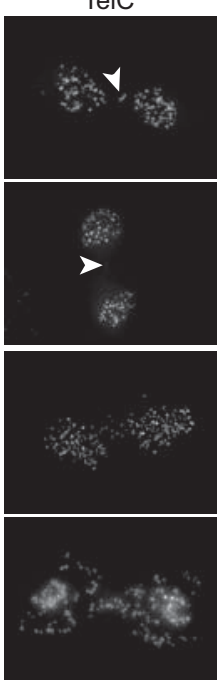

C
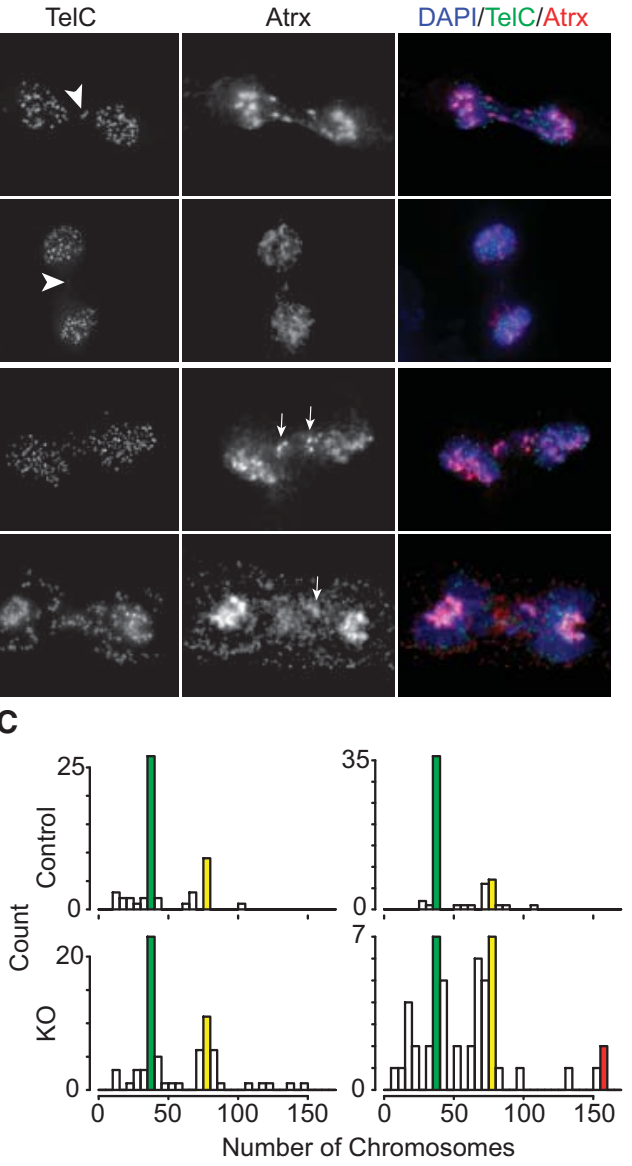

E

Figure 7. Mitotic defects, karyotypic abnormality, and DNA damage in $\mathrm{H} 3.3$ knockout $(\mathrm{KO}) / p^{2} 3^{\text {null }}$ MEFs. (A) Mitotic abnormalities of H3.3 knockout/ $p 53^{\text {null }}$ MEFs. ATRX immunofluorescence signal on lagging chromosomes (arrows) and telomere FISH sig$\mathrm{nal}(\mathrm{TelC})$ in the middle of bridging chromosomes (arrowheads) are indicated. (B) Percentages of mitotic cells with abnormalities in control and H3.3 knockout $/ p 53^{\text {null }}$ MEFs. Twenty-five mitotic events were scored in each line. $\left(^{* *}\right) P<0.01$ in $\chi^{2}$ test. $(C)$ Distribution of chromosome numbers counted in metaphase spreads made from H3.3 knockout $/ p 53^{\text {null }}$ MEF lines (bottom) and their littermate control lines (top). Colors denote close to normal $2 \mathrm{~N}(40)$ counts (green), $4 \mathrm{~N}$ (80) counts (yellow), and $8 \mathrm{~N}(160)$ counts (red). (D) rH2A.X levels in H3.3 knockout/p53 ${ }^{\text {null }}$ and control MEFs by Western blot. Lanes 2 and 4 are mutant cell lines, and lanes 1 and 3 are their littermate control lines, respectively. (E) Relative expression levels of H3.3 and rH2A.X calculated from $D$, normalized to total $\mathrm{H} 3$ level. $\left(^{*}\right) P<0.05$ in one-tailed $t$-test.

2008; O'Sullivan et al. 2014). Therefore, we also examined changes in the characteristic histone marks, including dimethylation at $\mathrm{H} 3 \mathrm{~K} 9$ and $\mathrm{H} 3 \mathrm{~K} 79$ and trimethylation at H3K9 and H3K36 (Jones et al. 2008; Chantalat et al. 2011), at pericentromeric (major satellite) and centromeric (minor satellite) regions and telomere repeats with ChIP-qPCR assays. No dramatic changes were found at the satellite repeats; however, there was a general trend of reduced $\mathrm{H} 3 \mathrm{~K} 9$ trimethylation and significant reduction of H3K36 dimethylation marks at the telomere (Fig. 8C). When global levels of these marks in H3.3-null cells were examined by Western blotting, we did not see a statistically significant reduction in any of the histone marks, but a general reduction of all of the marks was observed (Supplemental Fig. S7A,B).

Heterochromatin compaction at telomeres, centromeres, and pericentromeric regions plays an essential role for their functional integrity (Lange et al. 2013; Epis- kopou et al. 2014). To quantitatively measure the compactness of chromatin at these regions, we used the formaldehyde-assisted isolation of regulatory elements (FAIRE) technique, which is a sensitive method for detecting open chromatin regions in the genome /Giresi et al. 2007). In the FAIRE procedure, by chemical crosslinking, mechanical shearing, and organic extraction, nucleosome-free genomic DNA is enriched in the extract. H3.3-null cells always produced slightly higher yield than the controls (Supplemental Fig. S7C). This may be an indicator of more open chromatin regions in the genome. We used qPCR to quantify the relative enrichment of telomeric, centromere, and pericentromeric repeat sequences in each extract sample and found a significant increase in FAIRE signal with the H3.3-null cells (Fig. 8D). This indicates that the heterochromatin at these regions have adopted a more open structure in the absence of H3.3. 
A

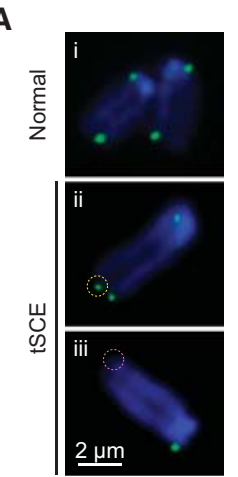

B
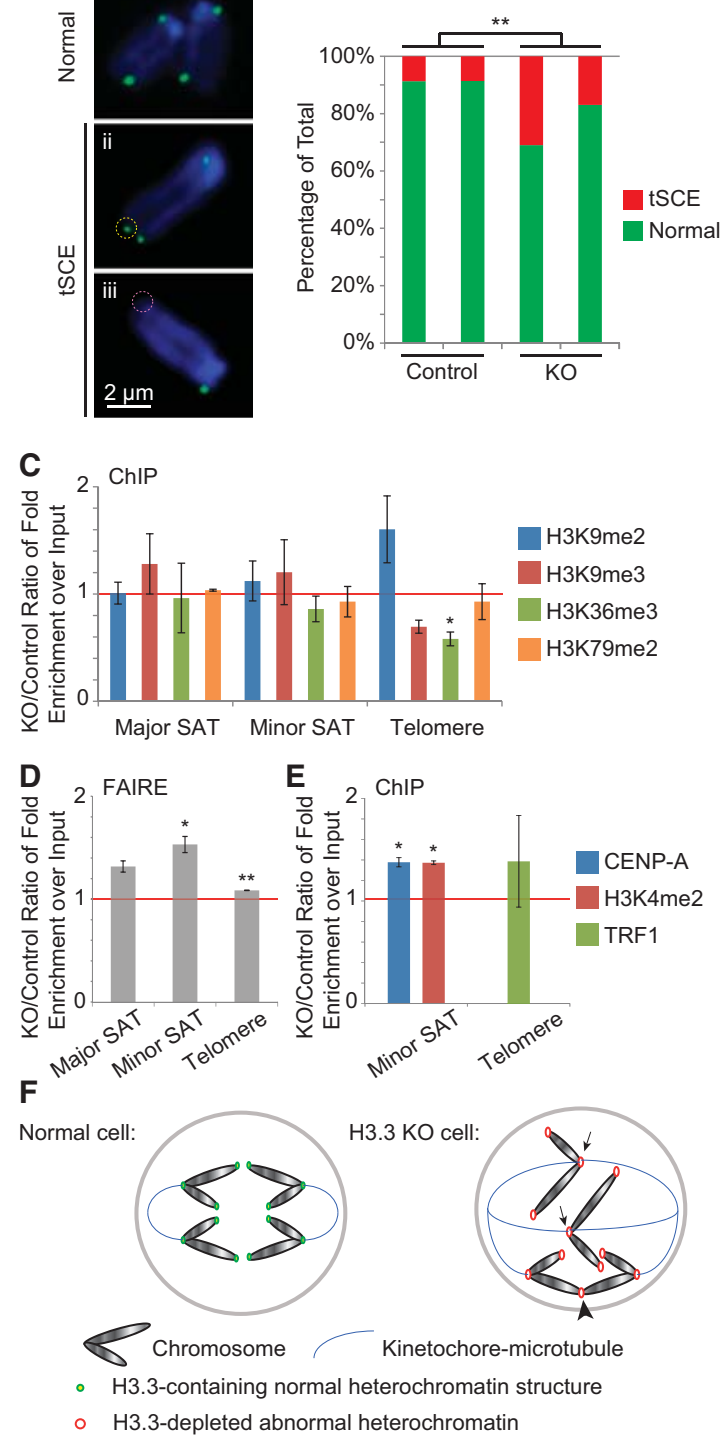

Figure 8. Telomere dysfunction and heterochromatin defects in H3.3 knockout (KO)/p53 ${ }^{\text {null }}$ MEFs. (A) CO-FISH results showing normal chromosomes (panel i) and chromosomes with tSCEs, which have either gained additional (yellow dashed circle) (panel ii) or lost (pink dashed circle) (panel iii) FISH signals. (B) Percentages of chromosomes with tSCEs in control and H3.3 knockout/ p53 ${ }^{\text {null }}$ MEF lines. $\left(^{* *}\right) P<0.01$ in $\chi^{2}$ test. $(C, E)$ ChIP-qPCR results with different antibodies and primers amplifying different repeat sequences. (D) FAIRE (formaldehyde-assisted isolation of regulatory elements)-qPCR results showing increased enrichment of repeat sequences in H3.3 knockout MEFs normalized to littermate control cell lines. In $C-E,\left(^{*}\right) P<0.05$ and $\left(^{* *}\right) P<0.01$ in one-tailed $t$-test. $(F)$ Model showing how loss of $\mathrm{H} 3.3$ affects chromosome segregation and genome integrity. Arrows point to aberrant organized kinetochores that lead to chromosome lagging. The arrowhead points to telomere fusion leading to the anaphase bridge.

To further investigate the possible causes of the centromeric and telomeric abnormalities in H3.3-null cells, we examined the expression levels and site-specific en- richments of centromeric histone $\mathrm{H} 3$ variant CENP-A, H3K4 dimethylation, and the double-stranded telomeric repeat-binding proteins TRF1 and TRF2. CENP-A defines centromere identity, and its incorporation is partly through replacing the so-called "placeholder" centromeric H3.3 during G1 phase (Dunleavy et al. 2011). H3K4 dimethylation is found between CENP-A nucleosome blocks (Sullivan and Karpen 2004). Thus, depletion of H3.3 could result in a reduction in CENP-A and corresponding $\mathrm{H} 3 \mathrm{~K} 4$ dimethlyation, causing segregation defects. TRF1 and TRF2 are DNA-binding proteins in the telomere-protecting complex shelterin, and their binding may be influenced by the local chromatin environment (Galati et al. 2015). Thus, without H3.3, shelterin may not bind to the telomeres, and this would result in a DNA damage response that leads to replicative senescence or apoptosis. Contrary to our expectations, CENPA binding and $\mathrm{H} 3 \mathrm{~K} 4$ dimethylation levels at centromeres increased proportionally in H3.3-depleted cells (Fig. 8E), suggesting a counterbalancing role for $\mathrm{H} 3.3$ in mediating the level of CENP-A binding and H3K4 dimethylation in the centromere. TRF1 binding to telomeres did not show consistent changes (Fig. 8E). To rule out nonspecific binding of the CENP-A and TRF antibodies, we confirmed their ChIP specificity (Supplemental Fig. S7D). We also quantified the global levels of CENP-A, H3K4 dimethylation, and the TRF proteins in the H3.3-null and control MEFs, and, while there appeared to be more of CENP-A and less of the TRF proteins, the differences were not statistically significant (Supplemental Fig. S7E,F).

\section{Discussion}

Our data provide an initial understanding of $\mathrm{H} 3.3$ function during mouse development. H3.3 is essential for mouse embryogenesis, as revealed in the double-knockout and Sox2-cKO experiments. All of the H3.3-null mutants die in utero with severe developmental retardation. This developmental retardation was caused in large part by p53-mediated cell death and cell cycle arrest, as we observed up-regulation of p53 targets that are directly involved in these processes, and, furthermore, a p53-null mutation effectively rescued the growth phenotype.

H3.3 appears largely dispensable for normal gene regulation in embryonic development. The rare double-knockout mutant embryos that survived past implantation showed correct embryonic patterning, indicated by their mesoderm marker gene expression pattern. The Sox2cKO embryos, albeit still growth-retarded, also showed correct patterning and functional cell differentiation. In addition, when the growth retardation phenotype was rescued by a p53 mutation, the Sox2-cKO-p5 $3^{\text {null }}$ embryos, with the exception of the neural tube closure defect and smaller size, developed with normal body plans and generated normal structures and organs.

The RNA-seq results provide further evidence that $\mathrm{H} 3.3$ has a limited role in transcriptional regulation during development. Although H3.3 was found enriched in all transcribed genes (Wirbelauer et al. 2005), only 5\% of transcribed genes were affected by its deletion. Because 
higher H3.3 incorporation and nucleosome turnover are positively associated with higher transcriptional levels (Deal et al. 2010), we expected highly transcribed genes in the control embryos to be more significantly reduced in double-knockout embryos. However, we did not observe an inverse correlation between fold changes and expression levels, and, surprisingly, even more genes were up-regulated in embryos without H3.3. Whether the affected genes were directly influenced by the absence of H3.3 incorporation into them or by cellular physiological changes altering other gene regulation mechanisms remains to be determined. However, with the transcriptome as a whole remaining largely intact without $\mathrm{H} 3.3$, we can conclude that $\mathrm{H} 3.3$ does not play a pivotal role in transcriptional regulation during mouse embryonic development. Our finding falls in line with an observation in H3.3-null flies, where H3.3 depletion affected relatively very few genes during embryonic development (Hodl and Basler 2009), although the reported compensatory up-regulation of canonic $\mathrm{H} 3$ variants in $\mathrm{H} 3.3$ mutant flies was not observed in the H3.3-null mouse embryos. From an evolutionary standpoint, H3.3 may have never played a dominant role in developmental gene regulation.

On the other hand, H3.3 appears to play a major role in maintaining genome integrity during development. In both ES cells and MEFs, H3.3 loss caused a dramatic increase of mitotic defects indicative of chromosome structure dysfunctions, including anaphase bridges and lagging chromosomes. Prolonged nonclearance of chromosomes at the midzone can delay mitosis and cause cleavage furrow regression, leading to endoreplication due to nonseparation of the duplicated genome (Pampalona et al. 2012). Lagging chromosomes may fail to integrate into the daughter nuclei and become lost, causing aneuploidy in subsequent cell divisions (Terradas et al. 2010). Accordingly, we observed a dramatic increase of polyploidy and aneuploidy in the H3.3 knockout $/ p 53^{\text {null }}$ MEFs. The p53-null background likely exacerbated the phenotype; otherwise, these cells with abnormal karyotypes should have been largely eliminated in the presence of wildtype p53 (Aylon and Oren 2011). In addition, anaphase bridges and lagging chromosomes in mitosis result in DNA damage (Hayashi and Karlseder 2013), as we observed increased $\mathrm{rH} 2 \mathrm{~A}$.X levels in these mutant cells. Karyotype abnormality and DNA damage accumulation are among the most common p53 pathway activators (Aylon and Oren 2011; Hayashi and Karlseder 2013), conferring on p53 the central role in mediating the H3.3-null mutant embryonic phenotype. In conclusion, an essential function of H3.3 in mouse development is to maintain genome integrity by supporting functional chromosome structures, ensuring a faithful partition of replicated genomes during cell division.

The dramatic induction of Cdkn2a upon H3.3 loss in a p53-null background lends further support to our model and helps explain the rescue phenotype. The two distinctive proteins encoded by $C d k n 2 a$-INK4A and ARF-are both critical tumor suppressors, albeit acting via different pathways (Kim and Sharpless 2006). INK4A binds CDK4/ 6 and stabilizes pRB protein, while ARF inactivates the p53 inhibitor MDM2 and thus activates the p53 pathway. Their expression can be stimulated by DNA damage and telomere dysfunction independent of p53 (Stott et al. 1998; Meng et al. 2003; Jacobs and de Lange 2004), and their cell cycle inhibition function is not solely dependent on p53 (Sherr et al. 2005; Britigan et al. 2014). In the Sox2-cKO-p53 ${ }^{\text {null }}$ embryos, the H3.3 ablation-induced telomere dysfunction and DNA damage are the canonic biological triggers for Cdkn2 expression, and the p53-independent cell cycle suppression mediated by ARF and INK4A likely leads to the imperfect rescue by the p53-null mutation that we observed; i.e., smaller embryo size, neural tube disclosure, and the inability to develop to term.

Epigenetic changes may be involved in the H3.3 deficiency-induced mitotic chromosomal abnormalities. The increase in tSCE is a strong indicator of compromised telomere function (Bailey et al. 2004). The decrease in H3K36 trimethylation at telomeres in H3.3-null cells suggests a role for H3.3 in its maintenance. Furthermore, we detected more open chromatin at the telomere, centromeres, and pericentromeric repeat regions in the H3.3null MEFs, indicating the involvement of H3.3 in heterochromatin compaction. The observed increase in H3K4 dimethylation and CENP-A binding at centromeres indicates abnormal changes in the centromeric chromatin environment. The observed changes may be the cause or, alternatively, a result of centromeric dysfunction in H3.3-depleted cells (Sullivan and Karpen 2004). How the lack of H3.3 as the "placeholder" for CENP-A deposition at the centromeres leads to the abnormal changes remains to be determined (Dunleavy et al. 2011).

Our results also suggest an intricate relationship between the ATRX chromatin remodeling complex and H3.3. The ATRX chromatin remodeling complex is known to mediate H3.3 incorporation at telomeres and pericentromeric heterochromatin (Goldberg et al. 2010), and the embryonic Sox2-cKO phenotypes bear a striking resemblance to that of an Atrx mutant (with Gata1-Creinduced global deletion at morula stage) (Garrick et al. 2006). Both H3.3 and Atrx knockouts induced growth retardation due to reduced cell proliferation and increased cell death without patterning defects; they even appear highly similar morphologically. ATRX's role in maintaining functional chromosome structures has been well documented. ATRX loss is associated with telomere dysfunction in cancer cells (Heaphy et al. 2011; Lovejoy et al. 2012). Loss of ATRX leads to centromere instability and aneuploidy in mouse oocytes and preimplantation embryos (Baumann et al. 2010). ATRX deficiency by conditional knockouts in neuronal cell lineages or RNAi knockdown in cultured cells induced cell death, telomere dysfunction, and prolonged mitosis, with defects including anaphase bridges and lagging chromosomes (Ritchie et al. 2008; Watson et al. 2013). These are the same defects that we observed in the H3.3 knockout MEFs. Furthermore, the cell death/tissue growth phenotypes of the Atrx conditional mutants can be effectively rescued in a p53-null background (Seah et al. 2008), reminiscent of the rescue that we observed in Sox2-cKO-p53 ${ }^{\text {null }}$ 
mutants. The increased tSCE phenotype in H3.3-null cells indicated telomere dysfunction, which is another well-documented feature of ATRX-deficient cells (Watson et al. 2013). All of the evidence suggests that H3.3 and ATRX cooperate to maintain or prepare chromosome structures for mitosis to proceed without errors. Therefore, even though the recruitment of ATRX to telomeres and the pericentromeric region appeared unaffected in the absence of H3.3, active incorporation of H3.3 into these heterochromatic structures by ATRX is essential for its normal function at these loci.

With these lines of evidence, we propose a model in which H3.3 maintains the histone marks and compact structures of the heterochromatin at telomeres, centromeres, and pericentromeric regions by either changing the chromatin properties through its presence at the sites or supporting the ATRX complex that remodels chromatin with repetitive sequences (Law et al. 2010). Loss of H3.3 leads to a decrease in these essential characteristics and disrupts the normal structure and function of telomeres and centromeres. The resulting telomere fusion and centromeric abnormalities eventually lead to the observed mitotic defects, including anaphase bridges and lagging chromosomes (Fig. 8F).

Contrary to previous studies showing compromised viability and fertility (Couldrey et al. 1999; Bush et al. 2013; Tang et al. 2013, 2015; Yuen et al. 2014), our single knockouts of $H 3 f 3 a$ and $H 3 f 3 b$ genes did not cause any obvious phenotype. This may be due to genetic background differences. The mice used in our experiments were from mixed backgrounds (mainly C57BL/6 and 129). The increased genetic heterogeneity may have contributed to the better viability and fertility of our knockouts as a result of hybrid vigor. Aside from the lack of phenotypes in the singleknockout mutants, the distinctive $A^{\text {null }} B^{\text {het }}$ and $A^{\text {het }} B^{\text {null }}$ compound mutant phenotypes shed some light on the evolution of the duplicated H3.3-encoding genes. There is an obvious functional redundancy between the $H 3 f 3 a$ and $H 3 f 3 b$ genes, since they encode the exact same amino acid sequence, and loss of either one fails to produce a phenotype. However, $A^{\text {Het }} B^{\text {null }}$ mice with only a single wild-type $H 3 f 3 a$ allele can survive to adulthood with only a male infertility phenotype, while the $A^{\text {null }} B^{\text {het }} \mathrm{mu}$ tants with only a single wild-type $H 3 f 3 b$ allele do not survive postnatally. These phenotypical differences probably reflect changes in promoter activity (either levels or patterns of expression) or post-transcriptional regulation ( $H 3 f 3 b$ has isoforms with long $3^{\prime}$ untranslated regions [UTRs]) of these two genes. Their differential expression patterns in different organs also support this argument$H 3 f 3 a$ has more uniform expression across organs, which may explain why a single $H 3 f 3 a$ allele is more supportive to mouse life than a single $H 3 f 3 b$.

The disappearance of germ cells in the $A^{\text {het }} B^{\text {null }}$ testis is also a very interesting phenotype. Germ cells may require more chromatin remodeling activities to maintain their special genomic functions; e.g., erasure of parental imprinting (Seki et al. 2005), leading to more H3.3 incorporation to the genome. Therefore, reduction of H3.3 may cause more dramatic transcriptional or chromosomal dis- turbances, leading to their demise. The high demand of H3.3 in germ cells is also reflected by the highest expression levels of both $H 3 f 3 a$ and $H 3 f 3 b$ genes in the testis compared with other organs. It will require more detailed studies to determine at what stage the germ cells are depleted and the exact causes.

\section{Materials and methods}

$q P C R$

For gene expression analysis, total RNA was extracted with Trizol (Life Technologies), treated with DNase I (Promega), and reverse-transcribed with ProtoScript II (New England Biolabs) and Random primer mix (New England Biolabs). Gene-specific primers are listed in Supplemental Table S6. Pancreas tissue was first dropped into RNAlater (Life Technologies) before further processing. 18S rRNA was used as the reference gene.

For genotyping, genomic DNA was extracted from adult tissue by alkaline lysis method. Tissue was placed in PCR strips; heated in $50 \mu \mathrm{L}$ of $25 \mathrm{mM} \mathrm{NaOH}, 0.2 \mathrm{mM}$ EDTA, and $0.04 \%$ Triton-X 100 for $1 \mathrm{~h}$ at $95^{\circ} \mathrm{C}$; neutralized with $50 \mu \mathrm{L}$ of $40 \mathrm{mM}$ Tris-HCl (pH unadjusted); and diluted with $100 \mu \mathrm{L}$ of water. Extract was cleaned by centrifugation at $3000 \mathrm{~g}$ for $10 \mathrm{~min}$. The supernatant was used as template in qPCR reaction. For embryonic tissue, genomic DNA was extracted by proteinase $\mathrm{K}$ digestion method. Tissue was digested in $20 \mu \mathrm{L}$ of $10 \mathrm{mM}$ TE 8.0 with $0.2 \%$ Triton-X 100 and $0.4 \mathrm{mg} / \mathrm{mL}$ proteinase $\mathrm{K}$ (added freshly before use) overnight at $56^{\circ} \mathrm{C}$, heat-inactivated for $10 \mathrm{~min}$ at $95^{\circ} \mathrm{C}$, diluted with water, and cleared by centrifugation.

SsoFast reagent (Bio-Rad) and CFX384 real-time system (BioRad) were used for qPCR. qPCR reactions were run with the following protocol: $3 \mathrm{~min}$ at $95.0^{\circ} \mathrm{C}$ and 40 times for $10 \mathrm{sec}$ at $95.0^{\circ} \mathrm{C}, 5 \mathrm{sec}$ at $60.0^{\circ} \mathrm{C}$, and $20 \mathrm{sec}$ at $72^{\circ} \mathrm{C}$ per plate read. Five microliters or $10 \mu \mathrm{L}$ of total reaction volume was used in reaction.

\section{Mouse strains}

The E14Tg2A.4 (E14) ES cell line (Skarnes 2000) was used for gene targeting. BAC clones of 129 genetic background bMQ107m17 and mMQ457f13 (Source BioScience) for $H 3 f 3 a$ and $H 3 f 3 b$ genes, respectively, were used for constructing targeting vectors. $\phi \mathrm{C} 31$ (Raymond and Soriano 2007) and FLPe (Farley et al. 2000) mice were used for deleting the Neo and gene trap cassettes, respectively. Primers for genotyping are listed in Supplemental Table S7.

\section{Cell culture}

For gene targeting, E14 cells were cultured in GMEM (Life Technologies) with $15 \%$ fetal calf serum (FCS), glutamine, sodium pyruvate, nonessential amino acids, penicillin/streptomycin, and ESGROW/LIF (Millipore) supplements on gelatin-coated plates without feeder.

Conditional ES cell lines were derived from blastocysts flushed from the uterus on $3.5 \mathrm{~d}$ post-coitum $(\mathrm{dpc})$ in crosses between $H 3 f 3 a^{f 1 / f 1} ; H 3 f 3 b^{f l / f 1}$ females and $H 3 f 3 a^{-/+} ; H 3 f 3 b^{-/+} ; C A G-$ $C r e E R^{T g / 0}$ males. They were maintained on $\gamma$-irradiated wildtype MEF feeders. Before the H3.3 knockout/sequencing experiments, they were passaged onto feeder-free plates with preplating on gelatin-coated plates to eliminate feeder cells. TAM was added into culture medium at $1 \mu \mathrm{g} / \mathrm{mL}$ concentration and changed daily. After $2 \mathrm{~d}$ of TAM treatment, cells were changed back into normal medium without TAM and cultured for another day for recovery before being harvested. 
MEFs for experiments were derived from E10.5 embryos. Whole embryos were minced into chunks of tissue by passing slowly through 19-gauge needles five to six times and plated on gelatin-coated plates. They were cultured in DMEM with 10\% FCS, glutamine, sodium pyruvate, nonessential amino acids, and penicillin/streptomycin. When MEFs that grew out from the chunks reached confluence, they were passaged, and the tissue chunks were filtered out with $100-\mu \mathrm{m}$ cell strainers (Fisher Scientific).

\section{Whole-mount in situ hybridization}

We followed the standard protocol for whole-mount in situ hybridization (Nagy 2003). Embryos were fixed in 4\% paraformaldehyde (PFA) and hybridized with probe labeled with digoxigenin11-UTP (Roche). Full-length cDNA of Brachyury was used as the template for probe synthesis. An anti-Dig-AP Fab (Roche) fragment and BM Purple (Roche) were used for detection and visualization of the hybridized probe.

\section{Lysotracker staining}

For Lysotracker staining, we follow the protocol as previously described (Fogel et al. 2012). Embryos were dissected in HBSS (Life Technologies), stained with LysoTracker Red DND-99 (Life Technologies), fixed in 4\% PFA, cleared in 50\% glycerol, and imaged.

\section{BrdU labeling}

Pregnant females were intraperitoneally injected with $50 \mathrm{mg} / \mathrm{kg}$ BrdU $3 \mathrm{~h}$ before being euthanized and having embryos dissected out. Embryos were fixed, sucrose-protected, and frozen-sectioned, antigen-retrieved by heating for $5 \mathrm{~min}$ to $85^{\circ} \mathrm{C}$ in $75 \%$ formamide/PBS, and detected with anti-BrdU antibody (1:200 dilution; Abcam, BU1/75 ICR1).

\section{Western blot}

Whole histone preparations were extracted by acid extraction as described (Shechter et al. 2007). Proteins were separated on $12.5 \%$ SDS-PAGE and detected with anti-H3.3 (1:40 dilution; Abnova, 2D7-H1), anti-H3 (1:10,000; Abcam, ab1791), and antirH2A.X (1:1000; Cell Signaling Technology, 20E3) antibodies; anti-H3K9 dimethylation (1:1000; Abcam, ab1220); anti-H3K9 trimethylation (1:1000; Abcam, ab8898); and anti-H3K79 dimethylation (1:1000; Abcam, ab3594).

\section{FISH and immunofluorescence}

Cells were grown on gelatin-coated coverslips, fixed with $4 \%$ PFA, in situ-hybridized with Alexa 488-conjugated TelC PNA oligo (PNA Bio, Inc.) following the manufacturer's instructions (except omitting RNase/pepsin treatments) and ethanol dehydration steps, and then immunostained with anti-ATRX primary (Santa Cruz Biotechnology, H-300) and then Alexa 568-conjugated secondary antibodies. Z-stack images were deconvolved and flattened by maximal intensity projection with AxioVision software (Carl Zeiss).

\section{Metaphase spreads and CO-FISH}

Cells were treated with KaryoMax (Life Technologies) for 4 h, trypsinized, hypotonized in $75 \mathrm{mM} \mathrm{KCl}$ for $10 \mathrm{~min}$, fixed in methanol with glacial acetic acid $(5: 2)$ overnight or longer at $4{ }^{\circ} \mathrm{C}$, dropped on distilled water-flooded uncoated slides, stained with DAPI, and imaged, and chromosomes were counted.

For CO-FISH, we followed the previously described protocol (Williams et al. 2011). Alexa 488-conjugated TelC PNA oligos (PNA Bio, Inc.) were used in hybridization. For scoring the tSCE phenotype, FISH signals were scored blind for statistical analyses. Comparable numbers of chromosomes (from 20-50 spreads) were scored for each pair of sibling MEF lines.

\section{ChIP-qPCR}

For histone ChIP, we followed the previously described protocol (Schmidt et al. 2009) with specific details as follows. Cells were fixed with $0.6 \%$ formaldehyde for $10 \mathrm{~min}$ at room temperature. Chromatin shearing was carried out in LB3 in 15-mL clear tubes with Bioruptor (Diagenode), with two rounds of six cycles of 30sec pulses (high) and 1-min breaks separated by a 10-min cool down on ice. Protein $\mathrm{A} / \mathrm{G}^{+}$agarose beads (Santa Cruz Biotechnology, sc-2003) were used. Antibodies were the same ones used in the Western blotting.

For Atrx ChIP, cells were fixed as previously described (Law et al. 2010). ChIP was carried out following the previously described MNase protocol (Kouskouti and Talianidis 2005) except omitting the sucrose gradient extraction step. Protein A/G Dynabeads (Life Technologies) were used. Anti-Atrx (Santa Cruz Biotechnology, H-300) and control rabbit IgG (Sigma, I5006) antibodies were used.

Primers for quantification of major/minor satellite and telomere repeat sequences are listed in Supplemental Table S6.

\section{FAIRE}

For FAIRE, we followed the previously described protocol (Simon et al. 2013). Cell fixation and chromatin shearing conditions were the same as in ChIP. Primer pairs are list in Supplemental Table S6.

\section{RNA-seq}

The RNA-seq library was prepared with KAPA stranded mRNAseq kit (KapaBiosystems, catalog no. KK8420), following the manufacturer's instructions, for $6 \mathrm{~min}$ at $85^{\circ} \mathrm{C}$ at the RNA fragmentation step. Total RNA was extracted from embryos with Trizol, DNase I-digested, and cleaned up with RNeasy columns (Qiagen). RNA samples $(0.5 \mu \mathrm{g})$ were used for library generation. Libraries were pooled (four per lane) and sequenced by Illumina HiSeq 2500 sequencer. The RNA-seq FASTQ files were aligned to the UCSC mm9 genome using TopHat2 (Trapnell et al. 2009) and Bowtie2 (Langmead and Salzberg 2012) using the iGenomes reference sequences (http://support.illumina.com/sequencing/ sequencing_software/igenome.ilmn) and annotations provided by Illumina. Annotation for REs came from RepeatMasker downloaded from the UCSC Genome Browser. Read counts per gene and RE were generated using HTSeq-count (http://wwwhuber.embl.de/users/anders/HTSeq/doc/count.html), and differential expression analysis was performed using edgeR (Robinson et al. 2010). Normalized BEDGraph files for UCSC genome browser tracks were generated using BEDTools /Quinlan and Hall 2010).

\section{Data access}

The RNA-seq data have been deposited in NCBI's Gene Expression Omnibus and are accessible through GEO series accession number GSE69771 (http://www.ncbi.nlm.nih.gov/geo/query/acc .cgi?acc=GSE69771). 


\section{Acknowledgments}

We thank all members of the Magnuson laboratory for helpful comments on manuscript preparation. We thank Dr. Gregory E. Crawford for his assistance in experiments and his critical input on the manuscript. This work was supported by National Institutes of Health grant RO1 GM101974.

\section{References}

Adam S, Polo SE, Almouzni G. 2013. Transcription recovery after DNA damage requires chromatin priming by the $\mathrm{H} 3.3$ histone chaperone HIRA. Cell 155: 94-106.

Aylon Y, Oren M. 2011. p53: guardian of ploidy. Mol Oncol 5: 315-323.

Bailey SM, Brenneman MA, Goodwin EH. 2004. Frequent recombination in telomeric DNA may extend the proliferative life of telomerase-negative cells. Nucleic Acids Res 32: 3743-3751.

Banaszynski LA, Wen D, Dewell S, Whitcomb SJ, Lin M, Diaz N, Elsasser SJ, Chapgier A, Goldberg AD, Canaani E, et al. 2013. Hira-dependent histone H3.3 deposition facilitates PRC2 recruitment at developmental loci in ES cells. Cell 155: 107120.

Baumann C, Viveiros M, De La Fuente R. 2010. Loss of maternal ATRX results in centromere instability and aneuploidy in the mammalian oocyte and pre-implantation embryo. PLoS Genet 6: e1001137.

Behjati S, Tarpey PS, Presneau N, Scheipl S, Pillay N, Van Loo P, Wedge DC, Cooke SL, Gundem G, Davies H, et al. 2013. Distinct H3F3A and H3F3B driver mutations define chondroblastoma and giant cell tumor of bone. Nat Genet 45: 1479-1482.

Britigan EM, Wan J, Zasadil LM, Ryan SD, Weaver BA. 2014. The ARF tumor suppressor prevents chromosomal instability and ensures mitotic checkpoint fidelity through regulation of Aurora B. Mol Biol Cell 25: 2761-2773.

Bush KM, Yuen BT, Barrilleaux BL, Riggs JW, O'Geen H, Cotterman RF, Knoepfler PS. 2013. Endogenous mammalian histone H3.3 exhibits chromatin-related functions during development. Epigenetics Chromatin 6: 7.

Chantalat S, Depaux A, Hery P, Barral S, Thuret JY, Dimitrov S, Gerard M. 2011. Histone H3 trimethylation at lysine 36 is associated with constitutive and facultative heterochromatin. Genome Res 21: 1426-1437.

Chen $\mathrm{P}$, Zhao J, Wang Y, Wang M, Long H, Liang D, Huang L, Wen Z, Li W, Li X, et al. 2013. H3.3 actively marks enhancers and primes gene transcription via opening higher-ordered chromatin. Genes Dev 27: 2109-2124.

Couldrey C, Carlton MB, Nolan PM, Colledge WH, Evans MJ. 1999. A retroviral gene trap insertion into the histone 3.3A gene causes partial neonatal lethality, stunted growth, neuromuscular deficits and male sub-fertility in transgenic mice. Hum Mol Genet 8: 2489-2495.

Cox SG, Kim H, Garnett AT, Medeiros DM, An W, Crump JG. 2012. An essential role of variant histone H3.3 for ectomesenchyme potential of the cranial neural crest. PLoS Genet 8: e1002938.

Davoli T, de Lange T. 2011. The causes and consequences of polyploidy in normal development and cancer. Annu Rev Cell Dev Biol 27: 585-610.

Deal RB, Henikoff JG, Henikoff S. 2010. Genome-wide kinetics of nucleosome turnover determined by metabolic labeling of histones. Science 328: 1161-1164.

Drane P, Ouararhni K, Depaux A, Shuaib M, Hamiche A. 2010. The death-associated protein DAXX is a novel histone chaper- one involved in the replication-independent deposition of H3.3. Genes Dev 24: 1253-1265.

Dunleavy EM, Almouzni G, Karpen GH. 2011. H3.3 is deposited at centromeres in $\mathrm{S}$ phase as a placeholder for newly assembled CENP-A in G(1) phase. Nucleus 2: 146-157.

Elsaesser SJ, Goldberg AD, Allis CD. 2010. New functions for an old variant: no substitute for histone H3.3. Curr Opin Genet Dev 20: 110-117.

Elsasser SJ, Noh KM, Diaz N, Allis CD, Banaszynski LA. 2015. Histone H3.3 is required for endogenous retroviral element silencing in embryonic stem cells. Nature 522: 240-244.

Episkopou H, Draskovic I, Van Beneden A, Tilman G, Mattiussi M, Gobin M, Arnoult N, Londono-Vallejo A, Decottignies A. 2014. Alternative Lengthening of Telomeres is characterized by reduced compaction of telomeric chromatin. Nucleic Acids Res 42: 4391-4405.

Farley FW, Soriano P, Steffen LS, Dymecki SM. 2000. Widespread recombinase expression using FLPeR (flipper) mice. Genesis 28: $106-110$.

Fogel JL, Thein TZ, Mariani FV. 2012. Use of LysoTracker to detect programmed cell death in embryos and differentiating embryonic stem cells. J Vis Exp 68: 4254.

Galati A, Micheli E, Alicata C, Ingegnere T, Cicconi A, Pusch MC, Giraud-Panis MJ, Gilson E, Cacchione S. 2015. TRF1 and TRF2 binding to telomeres is modulated by nucleosomal organization. Nucleic Acids Res doi: 10.1093/nar/gkv507.

Ganem NJ, Pellman D. 2012. Linking abnormal mitosis to the acquisition of DNA damage. J Cell Biol 199: 871-881.

Garrick D, Sharpe JA, Arkell R, Dobbie L, Smith AJ, Wood WG, Higgs DR, Gibbons RJ. 2006. Loss of Atrx affects trophoblast development and the pattern of X-inactivation in extraembryonic tissues. PLoS Genet 2: e58.

Giresi PG, Kim J, McDaniell RM, Iyer VR, Lieb JD. 2007. FAIRE (formaldehyde-assisted isolation of regulatory elements) isolates active regulatory elements from human chromatin. Genome Res 17: 877-885.

Goldberg AD, Banaszynski LA, Noh KM, Lewis PW, Elsaesser SJ, Stadler S, Dewell S, Law M, Guo X, Li X, et al. 2010. Distinct factors control histone variant H3.3 localization at specific genomic regions. Cell 140: 678-691.

Harada A, Okada S, Konno D, Odawara J, Yoshimi T, Yoshimura S, Kumamaru H, Saiwai H, Tsubota T, Kurumizaka H, et al. 2012. Chd2 interacts with H3.3 to determine myogenic cell fate. EMBO J 31: 2994-3007.

Hayashi MT, Karlseder J. 2013. DNA damage associated with mitosis and cytokinesis failure. Oncogene 32: 4593-4601.

Hayashi S, McMahon AP. 2002. Efficient recombination in diverse tissues by a tamoxifen-inducible form of Cre: a tool for temporally regulated gene activation/inactivation in the mouse. Dev Biol 244: 305-318.

Hayashi S, Lewis P, Pevny L, McMahon AP. 2002. Efficient gene modulation in mouse epiblast using a Sox2Cre transgenic mouse strain. Mech Dev 119: S97-S101.

Heaphy C, de Wilde R, Jiao Y, Klein A, Edil B, Shi C, Bettegowda C, Rodriguez F, Eberhart C, Hebbar S, et al. 2011. Altered telomeres in tumors with ATRX and DAXX mutations. Science 333: 425.

Herrmann BG. 1991. Expression pattern of the Brachyury gene in whole-mount TWis/TWis mutant embryos. Development 113: 913-917.

Hikisz P, Kilianska ZM. 2012. PUMA, a critical mediator of cell death-one decade on from its discovery. Cell Mol Biol Lett 17: 646-669.

Hodl M, Basler K. 2009. Transcription in the absence of histone H3.3. Curr Biol 19: 1221-1226. 
Hodl M, Basler K. 2012. Transcription in the absence of histone H3.2 and H3K4 methylation. Curr Biol 22: 2253-2257.

Inoue A, Zhang Y. 2014. Nucleosome assembly is required for nuclear pore complex assembly in mouse zygotes. Nat Struct Mol Biol 21: 609-616.

Jackson AL, Linsley PS. 2010. Recognizing and avoiding siRNA off-target effects for target identification and therapeutic application. Nat Rev Drug Discov 9: 57-67.

Jacobs JJ, de Lange T. 2004. Significant role for p16INK4a in p53-independent telomere-directed senescence. Curr Biol 14: 2302-2308.

Jin C, Felsenfeld G. 2007. Nucleosome stability mediated by histone variants H3.3 and H2A.Z. Genes Dev 21: 1519-1529.

Jin C, Zang C, Wei G, Cui K, Peng W, Zhao K, Felsenfeld G. 2009. H3.3/H2A.Z double variant-containing nucleosomes mark 'nucleosome-free regions' of active promoters and other regulatory regions. Nat Genet 41: 941-945.

Jones B, Su H, Bhat A, Lei H, Bajko J, Hevi S, Baltus GA, Kadam S, Zhai H, Valdez R, et al. 2008. The histone H3K79 methyltransferase Dot $1 \mathrm{~L}$ is essential for mammalian development and heterochromatin structure. PLoS Genet 4: e1000190.

Jonkers J, Meuwissen R, van der Gulden H, Peterse H, van der Valk M, Berns A. 2001. Synergistic tumor suppressor activity of BRCA2 and p53 in a conditional mouse model for breast cancer. Nat Genet 29: 418-425.

Jullien J, Astrand C, Szenker E, Garrett N, Almouzni G, Gurdon JB. 2012. HIRA dependent H3.3 deposition is required for transcriptional reprogramming following nuclear transfer to Xenopus oocytes. Epigenetics Chromatin 5: 17.

Kim WY, Sharpless NE. 2006. The regulation of INK4/ARF in cancer and aging. Cell 127: 265-275.

Kok FO, Shin M, Ni CW, Gupta A, Grosse AS, van Impel A, Kirchmaier BC, Peterson-Maduro J, Kourkoulis G, Male I, et al. 2015. Reverse genetic screening reveals poor correlation between morpholino-induced and mutant phenotypes in zebrafish. Dev Cell 32: 97-108.

Konev AY, Tribus M, Park SY, Podhraski V, Lim CY, Emelyanov AV, Vershilova E, Pirrotta V, Kadonaga JT, Lusser A, et al. 2007. CHD1 motor protein is required for deposition of histone variant $\mathrm{H} 3.3$ into chromatin in vivo. Science 317: 1087-1090.

Kouskouti A, Talianidis I. 2005. Histone modifications defining active genes persist after transcriptional and mitotic inactivation. EMBO J 24: 347-357.

Lange UC, Siebert S, Wossidlo M, Weiss T, Ziegler-Birling C, Walter J, Torres-Padilla ME, Daujat S, Schneider R. 2013. Dissecting the role of $\mathrm{H} 3 \mathrm{~K} 64 \mathrm{me} 3$ in mouse pericentromeric heterochromatin. Nat Commun 4: 2233.

Langmead B, Salzberg SL. 2012. Fast gapped-read alignment with Bowtie 2. Nat Methods 9: 357-359.

Law MJ, Lower KM, Voon HP, Hughes JR, Garrick D, Viprakasit V, Mitson M, De Gobbi M, Marra M, Morris A, et al. 2010. ATR-X syndrome protein targets tandem repeats and influences allele-specific expression in a size-dependent manner. Cell 143: 367-378.

Lewis PW, Elsaesser SJ, Noh KM, Stadler SC, Allis CD. 2010. Daxx is an H3.3-specific histone chaperone and cooperates with ATRX in replication-independent chromatin assembly at telomeres. Proc Natl Acad Sci 107: 14075-14080.

Lim CY, Reversade B, Knowles BB, Solter D. 2013. Optimal histone $\mathrm{H} 3$ to linker histone $\mathrm{H} 1$ chromatin ratio is vital for mesodermal competence in Xenopus. Development 140: 853-860.

Lin CJ, Conti M, Ramalho-Santos M. 2013. Histone variant H3.3 maintains a decondensed chromatin state essential for mouse preimplantation development. Development 140: 3624-3634.
Lin CJ, Koh FM, Wong P, Conti M, Ramalho-Santos M. 2014. Hira-mediated h3.3 incorporation is required for DNA replication and ribosomal RNA transcription in the mouse zygote. Dev Cell 30: 268-279.

Lovejoy CA, Li W, Reisenweber S, Thongthip S, Bruno J, de Lange T, De S, Petrini JH, Sung PA, Jasin M, et al. 2012. Loss of ATRX, genome instability, and an altered DNA damage response are hallmarks of the alternative lengthening of telomeres pathway. PLoS Genet 8: e1002772.

Loyola A, Almouzni G. 2007. Marking histone H3 variants: how, when and why? Trends Biochem Sci 32: 425-458.

McKittrick E, Gafken PR, Ahmad K, Henikoff S. 2004. Histone H3.3 is enriched in covalent modifications associated with active chromatin. Proc Natl Acad Sci 101: 1525-1530.

Meng A, Wang Y, Van Zant G, Zhou D. 2003. Ionizing radiation and busulfan induce premature senescence in murine bone marrow hematopoietic cells. Cancer Res 63: 5414-5419.

Nagy A. 2003. Manipulating the mouse embryo: a laboratory manual. Cold Spring Harbor Laboratory Press, Cold Spring Harbor, NY.

Ng RK, Gurdon JB. 2008. Epigenetic memory of an active gene state depends on histone H3.3 incorporation into chromatin in the absence of transcription. Nat Cell Biol 10: 102-109.

O'Sullivan RJ, Arnoult N, Lackner DH, Oganesian L, Haggblom C, Corpet A, Almouzni G, Karlseder J. 2014. Rapid induction of alternative lengthening of telomeres by depletion of the histone chaperone ASF1. Nat Struct Mol Biol 21: 167-174.

Pampalona J, Frias C, Genesca A, Tusell L. 2012. Progressive telomere dysfunction causes cytokinesis failure and leads to the accumulation of polyploid cells. PLoS Genet 8: e1002679.

Quinlan AR, Hall IM. 2010. BEDTools: a flexible suite of utilities for comparing genomic features. Bioinformatics 26: 841-842.

Raymond CS, Soriano P. 2007. High-efficiency FLP and $\phi$ C31 site-specific recombination in mammalian cells. PLoS One 2: e162.

Ritchie K, Seah C, Moulin J, Isaac C, Dick F, Berube NG. 2008. Loss of ATRX leads to chromosome cohesion and congression defects. J Cell Biol 180: 315-324.

Robinson MD, McCarthy DJ, Smyth GK. 2010. edgeR: a Bioconductor package for differential expression analysis of digital gene expression data. Bioinformatics 26: 139-140.

Rogakou EP, Pilch DR, Orr AH, Ivanova VS, Bonner WM. 1998. DNA double-stranded breaks induce histone $\mathrm{H} 2 \mathrm{AX}$ phosphorylation on serine 139. J Biol Chem 273: 5858-5868.

Sakai A, Schwartz B, Goldstein S, Ahmad K. 2009. Transcriptional and developmental functions of the H3.3 histone variant in Drosophila. Curr Biol 19: 1816-1836.

Schmidt D, Wilson MD, Spyrou C, Brown GD, Hadfield J, Odom DT. 2009. ChIP-seq: using high-throughput sequencing to discover protein-DNA interactions. Methods 48: 240-248.

Schwartzentruber J, Korshunov A, Liu XY, Jones DT, Pfaff E, Jacob K, Sturm D, Fontebasso AM, Quang DA, Tonjes M, et al. 2012. Driver mutations in histone H3.3 and chromatin remodelling genes in paediatric glioblastoma. Nature 482: 226-231.

Seah C, Levy MA, Jiang Y, Mokhtarzada S, Higgs DR, Gibbons RJ, Berube NG. 2008. Neuronal death resulting from targeted disruption of the Snf2 protein ATRX is mediated by p53. J Neurosci 28: 12570-12580.

Seki Y, Hayashi K, Itoh K, Mizugaki M, Saitou M, Matsui Y. 2005. Extensive and orderly reprogramming of genome-wide chromatin modifications associated with specification and early development of germ cells in mice. Dev Biol 278: 440-458. 
Shechter D, Dormann HL, Allis CD, Hake SB. 2007. Extraction, purification and analysis of histones. Nat Protoc 2: 14451457.

Sherr CJ, Bertwistle D, DEN Besten W, Kuo ML, Sugimoto M, Tago K, Williams RT, Zindy F, Roussel MF. 2005. p53-Dependent and -independent functions of the Arf tumor suppressor. Cold Spring Harb Symp Quant Biol 70: 129-137.

Simon JM, Giresi PG, Davis IJ, Lieb JD. 2013. A detailed protocol for formaldehyde-assisted isolation of regulatory elements (FAIRE). Curr Protoc Mol Biol 102: 21.26.1-21.26.15.

Skarnes WC. 2000. Gene trapping methods for the identification and functional analysis of cell surface proteins in mice. Methods Enzymol 328: 592-615.

Smith S, Stillman B. 1989. Purification and characterization of CAF-I, a human cell factor required for chromatin assembly during DNA replication in vitro. Cell 58: 15-25.

Stott FJ, Bates S, James MC, McConnell BB, Starborg M, Brookes S, Palmero I, Ryan K, Hara E, Vousden KH, et al. 1998. The alternative product from the human CDKN2A locus, p14(ARF), participates in a regulatory feedback loop with p53 and MDM2. EMBO I 17: 5001-5014.

Sullivan BA, Karpen GH. 2004. Centromeric chromatin exhibits a histone modification pattern that is distinct from both euchromatin and heterochromatin. Nat Struct Mol Biol 11: 1076-1083.

Szenker E, Ray-Gallet D, Almouzni G. 2011. The double face of the histone variant H3.3. Cell Res 21: 421-434.

Szenker E, Lacoste N, Almouzni G. 2012. A developmental requirement for HIRA-dependent H3.3 deposition revealed at gastrulation in Xenopus. Cell Rep 1: 730-740.

Tagami H, Ray-Gallet D, Almouzni G, Nakatani Y. 2004. Histone H3.1 and H3.3 complexes mediate nucleosome assembly pathways dependent or independent of DNA synthesis. Cell 116: 51-61.

Tang MC, Jacobs SA, Wong LH, Mann JR. 2013. Conditional allelic replacement applied to genes encoding the histone variant H3.3 in the mouse. Genesis 51: 142-146.

Tang MC, Jacobs SA, Mattiske DM, Soh YM, Graham AN, Tran A, Lim SL, Hudson DF, Kalitsis P, O'Bryan MK, et al. 2015. Contribution of the two genes encoding histone variant
H3.3 to viability and fertility in mice. PLOS Genet 11: e1004964.

Terradas M, Martin M, Tusell L, Genesca A. 2010. Genetic activities in micronuclei: is the DNA entrapped in micronuclei lost for the cell? Mutat Res 705: 60-67.

Trapnell C, Pachter L, Salzberg SL. 2009. TopHat: discovering splice junctions with RNA-seq. Bioinformatics 25: 11051111.

Verreault A, Kaufman PD, Kobayashi R, Stillman B. 1996. Nucleosome assembly by a complex of CAF- 1 and acetylated histones H3/H4. Cell 87: 95-104.

Warfel NA, El-Deiry WS. 2013. p21WAF1 and tumourigenesis: 20 years after. Curr Opin Oncol 25: 52-58.

Waterborg JH. 2012. Evolution of histone H3: emergence of variants and conservation of post-translational modification sites. Biochem Cell Biol 90: 79-95.

Watson LA, Solomon LA, Li JR, Jiang Y, Edwards M, Shin-ya K, Beier F, Berube NG. 2013. Atrx deficiency induces telomere dysfunction, endocrine defects, and reduced life span. J Clin Invest 123: 2049-2063.

Wen D, Banaszynski LA, Liu Y, Geng F, Noh KM, Xiang J, Elemento O, Rosenwaks Z, Allis CD, Rafii S. 2014. Histone variant $\mathrm{H} 3.3$ is an essential maternal factor for oocyte reprogramming. Proc Natl Acad Sci 111: 7325-7330.

Whitfield ML, Zheng LX, Baldwin A, Ohta T, Hurt MM, Marzluff WF. 2000. Stem-loop binding protein, the protein that binds the $3^{\prime}$ end of histone mRNA, is cell cycle regulated by both translational and posttranslational mechanisms. Mol Cell Biol 20: 4188-4198.

Williams ES, Cornforth MN, Goodwin EH, Bailey SM. 2011. CO-FISH, COD-FISH, ReD-FISH, SKY-FISH. Methods Mol Biol 735: 113-124.

Wirbelauer C, Bell O, Schubeler D. 2005. Variant histone H3.3 is deposited at sites of nucleosomal displacement throughout transcribed genes while active histone modifications show a promoter-proximal bias. Genes Dev 19: 1761-1766.

Yuen BT, Bush KM, Barrilleaux BL, Cotterman R, Knoepfler PS. 2014. Histone H3.3 regulates dynamic chromatin states during spermatogenesis. Development 141: 3483-3494. 


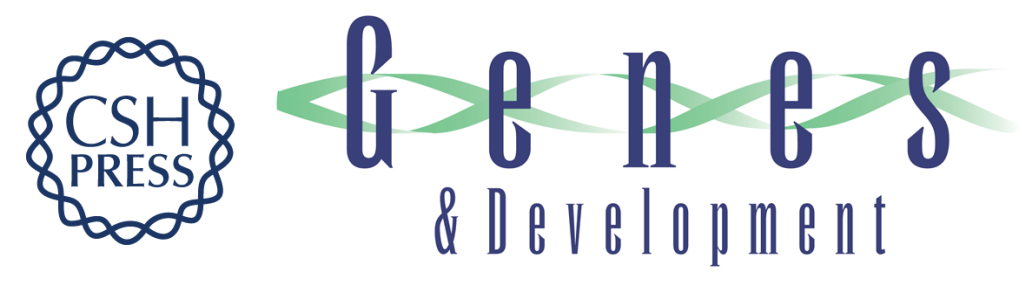

\section{Histone H3.3 maintains genome integrity during mammalian development}

Chuan-Wei Jang, Yoichiro Shibata, Joshua Starmer, et al.

Genes Dev. 2015, 29:

Access the most recent version at doi:10.1101/gad.264150.115

\section{Supplemental http://genesdev.cshlp.org/content/suppl/2015/07/09/29.13.1377.DC1 Material}

References This article cites 94 articles, 27 of which can be accessed free at: http://genesdev.cshlp.org/content/29/13/1377.full.html\#ref-list-1

Creative This article is distributed exclusively by Cold Spring Harbor Laboratory Press for the first Commons six months after the full-issue publication date (see

License http://genesdev.cshlp.org/site/misc/terms.xhtml). After six months, it is available under a Creative Commons License (Attribution-NonCommercial 4.0 International), as described at http://creativecommons.org/licenses/by-nc/4.0/.

Email Alerting Receive free email alerts when new articles cite this article - sign up in the box at the top Service right corner of the article or click here.

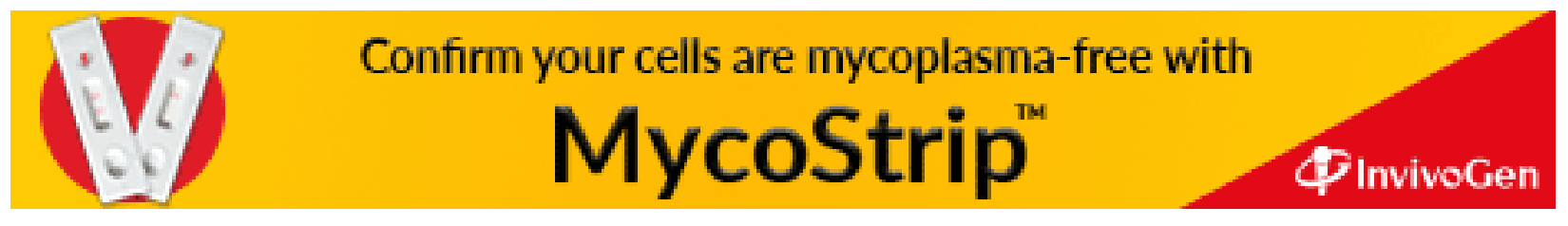

